\title{
Os processos de urbanização e conversão florestal na Amazônia paraense - um estudo multiescalar
}

\author{
Renata Maciel Ribeiro** \\ Silvana Amaral ${ }^{\star \star *}$ \\ Antônio Miguel Vieira Monteiro ${ }^{\star \star \star \star}$ \\ Ana Paula Dal'Asta ${ }^{\star \star \star \star \star}$
}

Na Amazônia brasileira, as dinâmicas de urbanização e conversão florestal possuem lógicas complexas, dependentes de fatores e agentes atuando em diferentes escalas. Este artigo explora a evolução espacial e temporal da urbanização e da conversão florestal na Amazônia, a partir de elementos mensuráveis presentes nestes processos: a expansão urbana, dimensão observável dos processos de urbanização; e o desmatamento, uma medida dos processos de conversão florestal. A identificação de padrões espaço-temporais similares, avaliados quanto às tendências de evolução temporal do grau de urbanização e incremento de desmatamento em 2000, 2010 e 2014, foi base para a proposta de uma tipologia das relações entre expansão urbana e desmatamento para os estados da Amazônia Legal e municípios do Pará. 0 estudo explorou também as relações entre expansão urbana e desmatamento, com uso de regressões geograficamente ponderadas (GWR), observando duas unidades espaciais de análise para o estado do Pará: os limites municipais e uma grade celular $(20 \times 20 \mathrm{~km})$. Esta abordagem multiescalar evidenciou a dificuldade de se estabelecerem relações conclusivas quanto à co-ocorrência, ou concordância, da evolução dos processos de urbanização e conversão florestal. Os resultados contribuem para o estabelecimento de uma agenda sobre modelos de desenvolvimento regional que retome 0 urbano como essencial para uma Amazônia socialmente justa e ambientalmente responsável.

Palavras-chave: Amazônia. Urbanização. Desmatamento. Análise espacial.

\footnotetext{
* Os autores agradecem o apoio do Instituto Nacional de Pesquisas Espaciais (Inpe), o suporte financeiro do Projeto 1022114003005 - MSA-BNDES, Sub-Projeto 5 - Trajetórias de Padrões e Processos na Caracterização de Novas Dinâmicas do Desmatamento na Amazônia - para a realização do trabalho de campo, bem como a bolsa Capes para o mestrado da primeira autora. Agradecem também aos pareceristas e editorial da Rebep pelas importantes contribuições para 0 aprimoramento do trabalho.

${ }^{* \star}$ Instituto Nacional de Pesquisas Espaciais (Inpe), São José dos Campos-SP, Brasil (renataribeiro@id.uff.br; https://orcid. org/0000-0003-3081-4446).

*** Instituto Nacional de Pesquisas Espaciais (Inpe), São José dos Campos-SP, Brasil (silvana.amaral@inpe.br; https:// orcid.org/0000-0003-4314-7291).

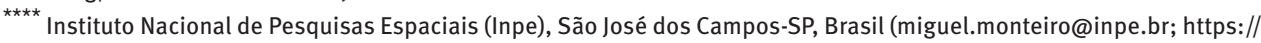
orcid.org/0000-0003-1477-1749).

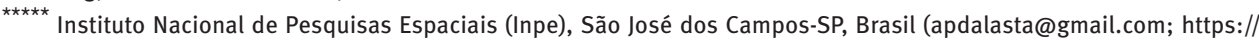
orcid.org/0000-0002-1286-9067).
} 


\section{Introdução}

Na Amazônia brasileira, a conversão florestal resulta em vários possíveis usos subsequentes para as áreas convertidas (MARGULIS, 2000, 2013; TRITSCH; TORNEAU, 2014). A transformação de área de floresta para área qualificada como uso urbano tem produzido, ao longo do tempo, reflexões sobre o papel da urbanização nos processos de conversão florestal, indicada ora como causa e ora como efeito. Quando caracterizada como causa, o crescimento da população urbana e a conversão direta para uso urbano são apontados como fatores condicionantes do desmatamento (CROPPER; GRIFFITHS, 1994; CARR, 2004; KIRBY et al., 2006; WRIGHT; MULLER-LANDAU, 2006). Quando indicada como efeito, a urbanização é discutida como o uso da terra resultante de fatores socioeconômicos subjacentes (MOLOTH, 1976; PERZ et al., 2005; DAL'ASTA et al., 2012; CARDOSO; NEGRÃO, 2013; BECKER, 2013; RICHARDS; VANWEY, 2015; TRITSCH; TORNEAU, 2014, 2016).

Diante de cenários de urbanização da população mundial e desmatamento em florestas tropicais, a hipótese de associação direta entre esses dois processos é discutida (CROPPER; GRIFFITHS, 1994; CARR, 2004; WRIGHT; MULLER-LANDAU, 2006). Para a realidade da Amazônia, autores diversos destacam a necessidade de abordagens multiescalares (AB'SABER, 1989; BECKER; EGLER, 1997; AMARAL et al., 2001, 2003, 2012; BARBIERI, 2007; ESCADA et al., 2009; ALVES et al., 2010; MELLO-THÉRY; THÉRY, 2014) e são unânimes ao apontar a multiplicidade de atores e processos históricos atuantes localmente.

Historicamente, a Amazônia é percebida por sua predominância de características rurais, embora mais de $70 \%$ de sua população resida em áreas oficialmente urbanas (IBGE, 2010a) e em processo de expansão (MONTE-MÓR, 1994; BECKER, 2013; RIBEIRO et al., 2017). 0 surgimento e a expansão das fronteiras urbanas da Amazônia, em seus diversos períodos, resultam de um perfil de desenvolvimento rápido, excludente e de natureza diversa, marcado por ciclos curtos de crescimento e queda da economia comandados, geralmente, por mercados exógenos à região (BECKER; STENNER, 2008; BECKER, 2001, 2009, 2013).

A intensificação da demanda por terras e a compreensão desta como um bem de consumo são apontados por Costa $(2012,2016)$ como fator importante para evolução do desmatamento na Amazônia. Cardoso et al. (2016) discutem que o mercado de terras tem influenciado não apenas o contexto rural, mas também a expansão de áreas urbanas. Assim, além do desmatamento associado ao histórico de atividades econômicas e processo de ocupação, os grandes circuitos de valorização da terra, por meio de loteamentos de espaços periurbanos, também respondem atualmente como agentes de conversão florestal.

Neste debate, o que se torna claro e consensual é que as dinâmicas de urbanização e conversão florestal possuem lógicas complexas que envolvem processos e agentes, situados nos territórios amazônicos, operando em diferentes escalas. Além do mercado de terras (CARDOSO et al., 2016), as redes de circulação viária (BECKER, 2001), a concentração de 
áreas protegidas (FERREIRA et al., 2005) e o interesse internacional no mercado de exportações (BECKER, 2001; RICHARDS; VANWEY, 2015) são, entre tantos outros aspectos, apontados como fatores relevantes às dinâmicas populacionais, de expansão de áreas urbanas e padrões de desmatamento na Amazônia.

Assim, o presente artigo procura explorar técnicas de análise para dados espaço-temporais para apreender e representar as relações entre os processos de conversão florestal e elementos observáveis da urbanização na Amazônia contemporânea. Destaca-se que o objetivo desta análise é investigar como os diferentes padrões de desmatamento ocorrem simultaneamente à evolução da urbanização, em suas dimensões populacional e territorial, e não estabelecer relações de causalidade. Para isso, são selecionados elementos mensuráveis destes processos, fazendo-se a ressalva de que tais medidas são apenas representações reduzidas de uma ou mais dimensões de um processo muito mais complexo. Estes elementos configuram uma estratégia de mediação (FEITOSA; MONTEIRO, 2012) para refletir sobre as questões em estudo. Neste contexto, a expansão urbana é a dimensão mensurável para a observação dos processos de urbanização em curso e o desmatamento é uma medida para os processos de conversão florestal.

A expansão urbana é observada, mensurada e representada pela evolução das áreas construídas, resultante de adensamento populacional, passíveis de identificação por sensoriamento remoto e pela evolução da população urbana - população residente em domicílios em áreas classificadas como urbanas (IBGE 2009), para o mesmo período de observação. A partir desta mediação, a urbanização, produto de processos de transformação política, econômica e social, é observada a partir da evolução no tempo de áreas urbanizadas e da população residente nessas áreas. Por sua vez, a conversão florestal refere-se à dimensão desmatamento, entendido como a perda completa da cobertura vegetal proveniente de floresta primária, do tipo corte raso, em área superior a 6,25 ha (INPE, 2006), mapeado anualmente pelo Programa de Monitoramento da Floresta Amazônica Brasileira (Prodes).

Neste novo contexto, tomando as dimensões mensuráveis expansão urbana e desmatamento como elementos de observação dos amplos e complexos processos relativos à urbanização e à conversão florestal, questiona-se: como ocorreram as evoluções, em período recente, da expansão urbana e do desmatamento nos territórios amazônicos? É possível descrever esta evolução? Existem padrões de evolução similares? Os padrões observados para a Amazônia Legal, tendo os estados como unidades espaciais de agregação, se repetiram em unidades espaciais mais finas, como os municípios? Existe associação espacial entre a expansão urbana e o desmatamento? Como se comporta, em diferentes unidades de análise, esta associação?

Para responder a estas questões, o presente artigo propõe um estudo conduzido para duas escalas - Amazônia Legal e Pará - e três unidades de análise - estados, municípios e células. Ressalta-se que as escalas neste trabalho são compreendidas, com base na proposta de Gibson et al. (2000), como as dimensões mensuráveis para apreender, medir e 
representar a relação entre os processos, enquanto as unidades de análise são os recortes territoriais que refletem a configuração do espaço regional.

Inicialmente, da caracterização das tendências de evolução temporal do grau de urbanização e incremento do desmatamento para 2000, 2010 e 2014, obtiveram-se um conjunto de padrões espaço-temporais desta relação e uma tipologia que classifica os estados da Amazônia Legal e os municípios do Pará. Em um segundo momento, foram exploradas as relações entre a expansão urbana e o desmatamento no mesmo período para os municípios do Pará, considerando duas unidades espaciais de análise: os limites municipais e as células de uma grade regular. Esta relação foi modelada por meio do uso de regressões geograficamente ponderadas (GWR) (BRUNSDON et al., 1996), identificando-se grupos de municípios e de células com comportamentos espaço-temporais similares. As próximas sessões apresentam uma caracterização da área de estudo, a abordagem metodológica e os resultados, que são discutidos à luz da literatura norteadora.

\section{Área de estudo}

A Amazônia Legal ${ }^{1}$ é um recorte espacial para fins de planejamento e abrange os estados do Acre, Amapá, Amazonas, Mato Grosso, Maranhão, Pará, Roraima, Rondônia e Tocantins. Com aproximadamente 24 milhões de residentes (IBGE, 2010), a Amazônia Legal teve seu processo histórico de ocupação associado, genericamente, a três grandes fases econômicas: extração e exportação do látex; projetos estatais de colonização; e avanço de agentes impulsionadores de mercados interno e externo conjugados ao poder público (BECKER, 2001, 2009; BECKER; STENNER, 2008; PRATES; BACHA, 2011).

Atualmente, no Pará, as atividades econômicas concentram-se no setor de extrativismo mineral e madeireiro, na agricultura e serviços; principalmente com expansão na agricultura, pela produção de soja (FAPESPA, 2016). As elevadas taxas de crescimento populacional (134 mil hab./ano de 1970 a 2010) (IBGE, 2010c) e o grau de urbanização (superior a 68\% em 2010) conferem ao estado o título de mais populoso da região Norte (IBGE, 2010b). Além do crescimento populacional, o Pará se distingue também por apresentar as maiores

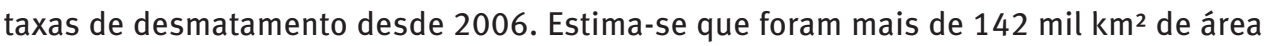
desmatada de 1988 a 2017, o que equivale em média a 34\% do desmatamento de toda a Amazônia Legal, segundo o projeto Prodes (INPE, 2017).

\footnotetext{
1 A Amazônia brasileira é definida pela Lei n. 1.806, de 06 de janeiro de 1953, e atualizada pela Lei Ordinária n. 5.173, de 27 de outubro de 1966. A Lei Complementar n. 124, de 3 de janeiro de 2007, atualiza a Lei Ordinária n. 5.173 e estabelece, em seu artigo 2ํㅡ, a atual definição para a Amazônia Legal como "A área de atuação da Sudam que abrange os estados do Acre, Amapá, Amazonas, Mato Grosso, Rondônia, Roraima, Tocantins, Pará e Maranhão, na sua porção a oeste do Meridiano 44”․
} 
FIGURA 1

Área de estudo
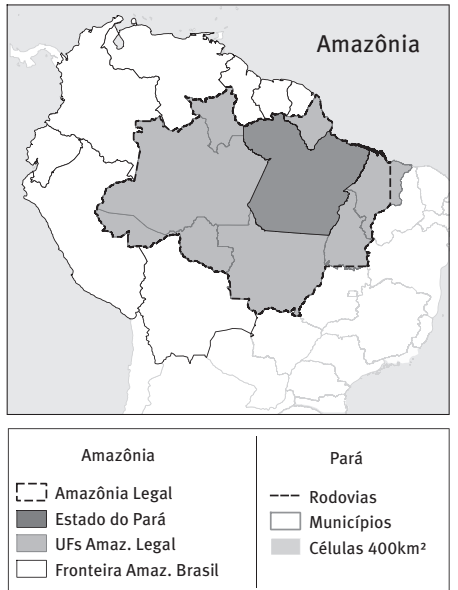

Sistema de Projeção: Lat Long DATUM: SAD 69

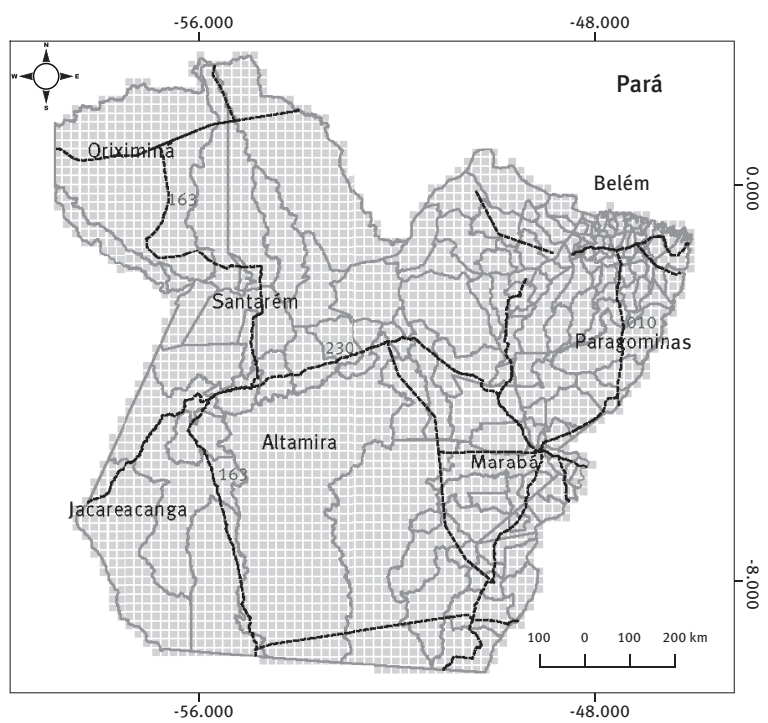

Fonte: IBGE (2000, 2010); Brasil (2010).

Ainda que questionável como indicador de desenvolvimento, o valor de PIB (Produto Interno Bruto) reflete as dinâmicas das atividades econômicas e impactos na economia. Em 2015, o estado do Pará contribuiu com 2,2\% do PIB nacional e 40,8\% do PIB da região Norte (FAPESPA, 2017) e, embora com diferenças regionais, demonstrou ser um estado de economia complexa, composta por atividades agropecuária, industrial e urbana. Por suas características econômicas, dinâmica populacional e de desmatamento, os municípios do Pará foram escolhidos para observar as relações entre urbanização e conversão florestal em escala mais fina (Figura 1).

\section{Procedimentos metodológicos}

Para a escala da Amazônia Legal, o território em análise é a região que abrange o recorte político-administrativo definido como Amazônia Legal. A dimensão espacial desta escala tem como extensão o limite da Amazônia Legal e como resolução, ou seja, como unidade espacial de referência, os estados desta região - incluindo o Maranhão. 0 método de análise nesta escala é a análise de tendências. A dimensão temporal tem como extensão o período de 2000 a 2014 e, como resolução, a análise anual de anos específicos desse período: 2000, 2010 e 2014. Para a escala do estado do Pará, a dimensão espacial tem como extensão o limite do estado do Pará e possui duas resoluções: os municípios do estado e uma grade regular com células de $20 \times 20 \mathrm{~km}$. A dimensão temporal tem como extensão o período de 2000 a 2014 e duas resoluções: a análise 
anual de anos específicos - 2000, 2010 e 2014 - e a análise referente à diferença entre 2014 e 2000. Os métodos de análise nesta escala são a análise de tendências e a análise de associações espaciais.

Considerando as diferentes escalas e, para o estado do Pará, as diferentes unidades espaciais (municípios e células), é importante destacar os possíveis efeitos do Maup (modifiable areal unit problem), o problema das unidades de área modificáveis. No contexto deste trabalho não é possível alterar as geometrias dos limites municipais, estaduais e dos setores censitários. No caso dos dados do IBGE, são estas as unidades espaciais de referência de acesso público e oferecidas para os estudos. Em relação aos produtos de sensoriamento remoto, o mapeamento de área urbana do TerraClass e o mapeamento de desmatamento do Prodes são obtidos considerando uma unidade espacial de referência básica, um elemento de imagem com 30×30m de resolução. Estas unidades básicas (setores censitários e pixels) são então agregadas pelos limites estaduais e municipais, que não se modificam, e por células de $20 \times 20 \mathrm{~km}$, que podem se modificar em seu tamanho, mas não em sua configuração.

Destaca-se que este estudo não trabalha com inferência estatística na busca de predição e, mesmo quando usa a análise de regressão, seu objetivo é explorar a variabilidade espacial da relação em estudo. Ainda assim, estatisticamente, foram escolhidos modelos (GWR) em que as mudanças de seus parâmetros ao longo das diferentes posições na região estudada podem ser acomodadas, e isso pode ajudar a inferir sobre o comportamento das variáveis de interesse.

Parte 1 - Análise de tendências da expansão urbana e desmatamento: Amazônia Legal e Pará

A relação do desmatamento e expansão urbana foi estudada a partir de análise de tendências gerais, buscando uma tipologia de padrões descritivos da evolução dessa relação. 0 grau de urbanização (GU) foi considerado a medida populacional da expansão urbana (Quadro 1). Para seu cálculo, foram utilizados os dados de população urbana e total dos Censos 2000 e 2010 - para os estados e municípios (IBGE, 2000, 2010). E, para 2014, a população total refere-se aos dados da estimativa populacional (IBGE, 2014) e a população urbana foi estimada com base na metodologia proposta por Madeira e Simões (1972). Nesta metodologia, a população urbana, de uma determinada data para uma determinada unidade territorial de análise, é função do volume populacional da unidade territorial imediatamente superior e estimada a partir de coeficientes calculados para os anos de resultados de universo do Censo Demográfico (IBGE, 2000, 2010). Como medida de desmatamento no período analisado (2000, 2010 e 2014), adotou-se o incremento anual medido pelo Prodes (INPE, 2015) (Quadro 1).

A tipologia de padrões quanto à evolução das variáveis de expansão urbana e desmatamento foi definida empiricamente a partir da observação dos gráficos das intensidades das variáveis nos três períodos de análise - 2000, 2010 e 2014. As unidades espaciais 
(estados e municípios) com evolução temporal similares para ambas variáveis foram agrupadas, refletindo as dinâmicas conjuntas de aumento, decréscimo ou estabilidade.

QUADRO 1

Descrição das variáveis utilizadas

\begin{tabular}{|c|c|c|c|c|}
\hline \multicolumn{2}{|r|}{ Variáveis } & Descrição & Data & Fonte \\
\hline \multirow{3}{*}{ 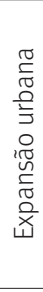 } & Área urbana (2) & $\begin{array}{c}\text { Áreas construídas e características de } \\
\text { infraestrutura urbana (arruamento, } \\
\text { prédios, lotes, etc.) }\end{array}$ & $\begin{array}{l}2004 \mathrm{e} \\
2014\end{array}$ & $\begin{array}{l}\text { Projeto TerraClass (INPE, } \\
2004,2014)\end{array}$ \\
\hline & $\begin{array}{l}\text { População urbana (2) } \\
\text { (no de habitantes) }\end{array}$ & $\begin{array}{l}\text { População residente em setores } \\
\text { censitários urbanos }\end{array}$ & $\begin{array}{l}2000 \\
2010 \mathrm{e} \\
2014\end{array}$ & $\begin{array}{l}\text { Censo } 2000 \text { e } 2010 \\
\text { (IBGE, 2000, 2010) e } \\
\text { estimativa 2014* }\end{array}$ \\
\hline & Grau de urbanização (1) & $\begin{array}{l}\text { Porcentagem de população urbana } \\
\text { em relação à população total }\end{array}$ & $\begin{array}{l}2000 \\
2010 \mathrm{e} \\
2014\end{array}$ & $\begin{array}{l}\text { Censo } 2000 \text { e } 2010 \\
\text { (IBGE, 2000, 2010) e } \\
\text { estimativa 2014* }\end{array}$ \\
\hline \multirow{2}{*}{ 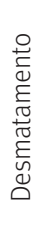 } & $\begin{array}{l}\text { Incremento anual (1) } \\
\left(\mathrm{km}^{2}\right)\end{array}$ & $\begin{array}{c}\text { Adicional de desmatamento corte } \\
\text { raso do ano vigente (t2) em relação } \\
\text { ao ano anterior (t1), sem considerar a } \\
\text { cobertura de nuvens e diferenças na } \\
\text { data de aquisição da imagem }\end{array}$ & $\begin{array}{l}2001 \\
2010 \mathrm{e} \\
2014\end{array}$ & $\begin{array}{l}\text { Programa Prodes } \\
\text { (INPE, 2015) }\end{array}$ \\
\hline & $\begin{array}{l}\text { Desmatamento } \\
\text { acumulado (2) } \\
\qquad\left(\mathrm{km}^{2}\right)\end{array}$ & $\begin{array}{l}\text { Total de área desmatada até o } \\
\text { período }\end{array}$ & $\begin{array}{l}2000 \mathrm{e} \\
2014\end{array}$ & $\begin{array}{l}\text { Programa Prodes } \\
\text { (INPE, 2015) }\end{array}$ \\
\hline
\end{tabular}

Fonte: Almeida et al. (2016); IBGE (2000, 2010, 2014); Inpe (2015).

(1) Utilizado para a análise de tendências (primeira parte).

(2) Utilizado para regressão espacial local (segunda parte).

* Estimados com base na metodologia de Madeira e Simões (1972)

\section{Parte 2 - Associação espacial entre a expansão urbana e o desmatamento: Pará}

Os distintos históricos de ocupação da Amazônia brasileira, sua vasta extensão territorial e características geográficas locais resultam em significativas diferenças intrarregionais. A documentada heterogeneidade associada ao processo de conversão florestal (AGUIAR, 2007; PRATES, 2008) e urbanização (HOGAN et al., 2008; BECKER, 2009, 2013) e a necessidade de compreender as especificidades no espaço regional como "quadro de referência básica para ação política” (BECKER, 2001, p. 155) levam ao questionamento quanto à eficiência de propostas metodológicas que tratam estes processos de forma homogênea no território. Alternativamente, é possível explorar as relações entre variáveis a partir da perspectiva local, utilizando regressões geograficamente ponderadas (GWR) (BRUNSDON et al., 1996).

As GWR permitem a estimação de regressões lineares localizadas, tratando a não estacionaridade de modelos que apresentem variáveis complexas com dinâmicas e respostas heterogêneas. A partir de coeficientes de regressões locais, aplicam-se regressões lineares para cada unidade espacial homogênea, utilizando uma subamostra de dados, baseada nas observações de vizinhança:

$Y_{i}=\beta_{0}\left(u_{i}, v_{i}\right)+\Sigma_{k} \beta_{k}\left(u_{i}, v_{i}\right) x_{i k}+\varepsilon_{i}$

Onde $\left(u_{i}, v_{i}\right)$ representa as coordenadas do ponto $i$ no espaço e $\beta_{k}\left(u_{i}, v_{i}\right)$ refere-se ao valor que a função contínua $\beta_{k}(u, v)$ assume no ponto $i$. 
Dois modelos foram propostos para observação no espaço da evolução do processo de expansão urbana em relação à evolução do processo de desmatamento. Para a expansão urbana foram utilizadas a diferença de área urbana ( $\triangle$ Área Urbana), proveniente do mapeamento da classe "área urbana" do projeto TerraClass (ALMEIDA et al., 2016) (equação 2), e a diferença de população urbana ( $\Delta$ Pop. Urbana), proveniente de dados censitários e estimativa (IBGE, 2000, 2014) (equação 3). Assim como na primeira etapa, para o ano de 2014 a população urbana foi estimada com base na metodologia de Madeira e Simões (1972). Para o desmatamento, utilizou-se a diferença de área de desmatamento acumulado ( $\triangle$ Desmatamento Acumulado), do projeto Prodes (INPE, 2015) (Quadro 1 e Figura 2). Para análise da adequailidade do modelo aos pressupostos de linearidade, as variáveis passaram por transformação logarítmica e valores atípicos foram retirados do conjunto populacional.

$\log (\Delta(\text { Área Urbana }))_{i}=\beta_{0}\left(u_{i}, v_{i}\right)+\beta_{1}\left(u_{i}, v_{i}\right) \log (\Delta(\text { Desmat. Acumulado }))_{i}+\varepsilon_{i}$

$\log (\Delta(\text { Pop. Urbana }))_{i}=\beta_{0}\left(u_{i}, v_{i}\right)+\beta_{1}\left(u_{i}, v_{i}\right) \log (\Delta(\text { Desmat. Acumulado }))_{i}+\varepsilon_{i}$

FIGURA 2

Diferenças $(\Delta)$ de área urbana, população urbana e desmatamento acumulado no período de 2000 a 2014 nos polígonos municipais e células do estado do Pará

$\Delta$ Área Urbana $\left(\mathrm{km}^{2}\right)$

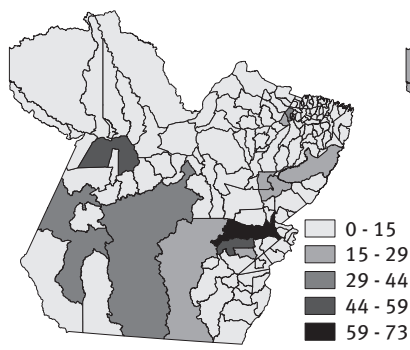

$\Delta$ Área Urbana $\left(\mathrm{km}^{2}\right)$

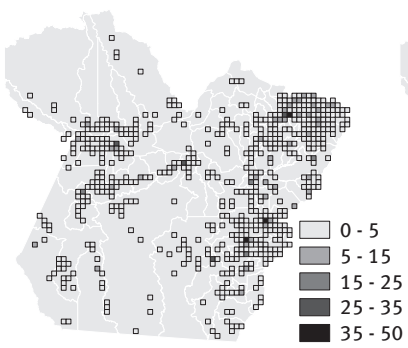

$\Delta$ Pop. Urbana (hab./mil)

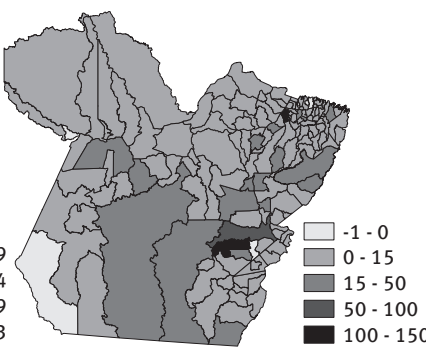

$\Delta$ Pop. Urbana (hab./mil)

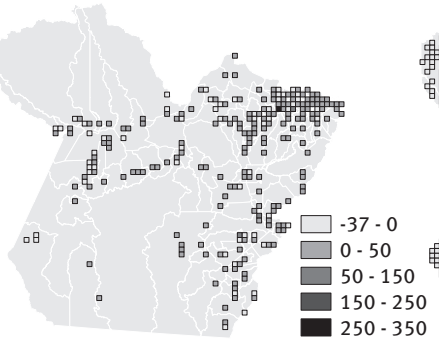

$\Delta$ Desmat. Acum. $\left(\mathrm{km}^{2} / \mathrm{mil}\right)$

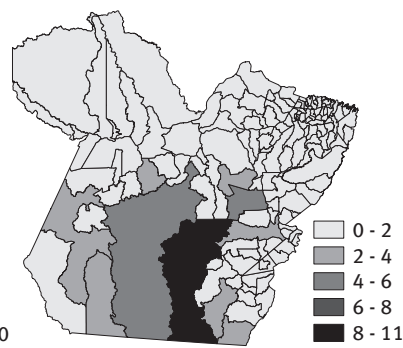

$\Delta$ Desmat. Acum. $\left(\mathrm{km}^{2}\right)$

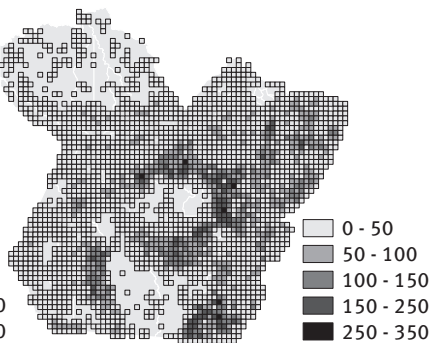

Fonte: Almeida et al. (2016); IBGE (2000, 2010, 2014); Inpe (2015).

Considerando-se que distorções nos resultados são possíveis devido à diferença de tamanho de área dos municípios no estado do Pará, para estudar o efeito da mudança de 
resolução na escala, foram adotadas duas unidades espaciais: os limites dos municípios e um espaço de células regulares, levando em conta a distribuição contínua dos processos, dissociada dos limites políticos-administrativos. Para compatibilizar as unidades de análise, sem comprometer o processamento dos dados, células de $20 \times 20 \mathrm{~km}$ foram estabelecidas. Destaca-se que para as células foi utilizada a mesma base de dados das variáveis de área urbana, população urbana e desmatamento dos municípios, contudo, em seus formatos vetoriais.

No caso da variável de população urbana, a associação à grade regular foi feita por método dasimétrico (LANGFOR; UNWIN, 1994; MENNIS, 2003), usando o operador de soma ponderada por área - de modo a garantir a preservação dos volumes e unidades de cada variável - para redistribuir a população dos setores censitários urbanos de 2000 e 2010 (IBGE, 2000, 2010) por célula. Após isso, foi feita a estimativa de população urbana para 2014 com base no método de Madeira e Simões (1972). Para as variáveis de área (área urbana e desmatamento), foi realizada a desagregação dos produtos de sensoriamento remoto, do projeto TerraClass (ALMEIDA et al., 2016) e Prodes (INPE, 2015), com o mesmo operador (soma ponderada por área).

Anteriormente à modelagem GWR, foram avaliados os pressupostos de linearidade $e$ verificada a presença de efeitos espaciais nos modelos. A normalidade dos resíduos foi analisada com base no teste estatístico Jarque-Bera, significante em 0,05 (hipótese nula rejeitada) para os modelos de área urbana $(k=2)$ e população urbana $(k=4)$ na resolução celular, e para o modelo de população urbana $(k=4)$ na resolução municipal. De modo similar, a homocedasticidade dos resíduos foi analisada com base nos testes estatísticos Breusch-Pagan e Koenker-Basset, significantes em 0,05 para os modelos de área urbana $(k=2)$ e população urbana $(k=4)$ na resolução municipal, e para o modelo de população urbana $(k=4)$ na resolução celular. Este resultado revela a não estacionariedade dos modelos mesmo após transformação logarítmica e indica a necessidade de aplicação de métodos espaciais para a análise proposta. 0 valor $k$ foi estabelecido segundo procedimento proposto por Baumont (2004). A partir deste critério, define-se que o número ideal $k$ de vizinhos mais próximos é o número que obtém no resíduo do modelo o maior valor do índice I de Moran.

Os dois modelos (área urbana e população urbana) nas duas unidades (municípios e células), além de indicarem não estacionariedade, obtiveram baixos valores de coeficiente de determinação $\left(\mathrm{R}^{2}\right)$ (Anexo), corroborando as hipóteses de não correlação entre os processos. Este resultado mostra que os processos de expansão de áreas urbanas, população urbana e desmatamento, apesar de dissociados no tempo, podem ser influenciados por estruturas de autocorrelação espacial.

Tendo em vista os resultados obtidos na análise de regressão não espacial, indicando que não há estabilidade espacial de primeira e segunda ordens, além dos objetivos investigativos da pesquisa e a heterogeneidade espacial dos processos discutida em literatura, 
deu-se continuidade à análise espacial e foi aplicada a GWR. Devido à natureza dos dados, escolheu-se um modelo GWR gaussiano tradicional, em que cada município foi identificado pelas coordenadas de suas sedes municipais, e cada célula pelo seu centro de massa. Por se tratar de pontos amostrais não contíguos, em que a distância entre os pontos 0 (zero) são irregulares, adotou-se a função kernel adaptativa de ponderação de distância, e critério de seleção de banda automático - golden section - (GREIG, 1980) com base no método de validação cruzada (CV).

Não sendo detectada correlação (nula ou baixa) entre as variáveis de expansão urbana e desmatamento, aceita-se a hipótese de independência entre os fenômenos como anteriormente discutida por Moloth (1976), Perz et al. (2005), Dal'Asta et al. (2012), Cardoso e Negrão (2013), Becker (2013), Richards e Vanwey (2015) e Tritsch e Torneau (2014, 2016).

\section{Resultados e discussões}

\section{Parte 1 - Primeiros traços de heterogeneidade}

A análise conjunta das intensidades anuais do grau de urbanização (GU) e incremento de desmatamento evidenciou uma tipologia das dinâmicas para os estados (Quadro 2) e outra análoga para os municípios (Quadro 3).

QUADRO 2

Tipologia da evolução simultânea do incremento de desmatamento e GU (2000-2010-2014) para os estados da Amazônia Legal

\begin{tabular}{|c|c|c|c|}
\hline Grupos & Incremento & $\begin{array}{l}\text { Grau de } \\
\text { urbanização } \\
\text { (GU) }\end{array}$ & Descrição \\
\hline I & & & $\begin{array}{l}\text { Redução do desmatamento até } 2010 \text { e aumento } \\
\text { em 2014; GU com aumento em todo período, } \\
\text { com maior variação entre } 2010 \text { e } 2014 \text {. }\end{array}$ \\
\hline II & & & $\begin{array}{l}\text { Redução do desmatamento, com maior } \\
\text { intensidade entre } 2000 \text { e } 2010 ; \text { GU crescente, } \\
\text { com maior variação entre } 2010 \text { e } 2014 \text {. }\end{array}$ \\
\hline III & & & $\begin{array}{l}\text { Redução do desmatamento até } 2010 \text { e aumento } \\
\text { em 2014; GU com aumento em todo período, } \\
\text { com maior variação entre } 2000 \text { e } 2010 \text {. }\end{array}$ \\
\hline
\end{tabular}

Fonte: IBGE (2000, 2010, 2014); Inpe (2015). 


\section{QUADRO 3}

Tipologia da evolução simultânea do incremento de desmatamento e GU (2000-2010-2014) para os municípios do Pará

\begin{tabular}{|c|c|c|c|}
\hline Grupos & Incremento & $\begin{array}{l}\text { Grau de } \\
\text { urbanização } \\
\text { (GU) }\end{array}$ & Descrição \\
\hline 1 & & & $\begin{array}{l}\text { Redução do desmatamento, com maior } \\
\text { variação entre } 2000 \text { e } 2010 ; \mathrm{GU} \text { decrescente } \\
\text { em todo período. }\end{array}$ \\
\hline 2 & & & $\begin{array}{l}\text { Redução do desmatamento, com maior } \\
\text { variação entre } 2000 \text { e } 2010 ; \text { GU decrescente, } \\
\text { com maior variação entre } 2000 \text { e } 2010 \text {. }\end{array}$ \\
\hline 3 & & & $\begin{array}{l}\text { Redução do desmatamento, com maior } \\
\text { variação entre } 2000 \text { e 2010; GU crescente } \\
\text { em todo período. }\end{array}$ \\
\hline 4 & & & $\begin{array}{l}\text { Redução do desmatamento, com maior } \\
\text { variação entre } 2000 \text { e } 2010 ; \text { GU crescente, } \\
\text { com maior variação entre } 2000 \text { e } 2010 \text {. }\end{array}$ \\
\hline 5 & & & $\begin{array}{l}\text { Redução do desmatamento, com maior } \\
\text { variação entre } 2000 \text { e } 2010 ; \text { GU crescente, com } \\
\text { maior variação entre } 2010 \text { e } 2014 \text {. }\end{array}$ \\
\hline 6 & & & $\begin{array}{l}\text { Redução do desmatamento, com maior } \\
\text { variação entre } 2010 \text { e } 2014 ; \text { GU crescente, } \\
\text { com maior variação entre } 2000 \text { e } 2010 \text {. }\end{array}$ \\
\hline 7 & & & $\begin{array}{l}\text { Redução do desmatamento, com maior } \\
\text { variação entre } 2010 \text { e } 2014 ; \text { GU decrescente, } \\
\text { com maior variação entre } 2000 \text { e } 2010 \text {. }\end{array}$ \\
\hline 8 & & & $\begin{array}{l}\text { Redução do desmatamento até } 2010 \text { e } \\
\text { aumento a partir de 2014; GU crescente, } \\
\text { com maior variação entre } 2000 \text { e } 2010 \text {. }\end{array}$ \\
\hline 9 & & & $\begin{array}{l}\text { Aumento do desmatamento até } 2010 \text { e } \\
\text { redução a partir de } 2014 \text {; GU crescente, com } \\
\text { maior variação entre } 2000 \text { e } 2010 \text {. }\end{array}$ \\
\hline 10 & & & $\begin{array}{l}\text { Aumento do desmatamento até } 2010 \text { e } \\
\text { redução a partir de 2014; GU decrescente, } \\
\text { com maior variação entre } 2000 \text { e } 2010 \text {. }\end{array}$ \\
\hline - & & & Padrões não replicáveis. \\
\hline
\end{tabular}

Fonte: IBGE (2000, 2010, 2014); Inpe (2015).

A Figura 3 apresenta os padrões observados para as diferentes escalas e suas tipologias. De modo geral, observam-se diversificados padrões de relação entre as dinâmicas de desmatamento e expansão urbana, refletindo as particularidades históricas do processo de ocupação e uso da terra em cada localidade. 
FIGURA 3

Representação dos padrões de similaridades nas dinâmicas do GU e incremento de desmatamento em 2000, 2010 e 2014 para os estados da Amazônia Legal e municípios do Pará
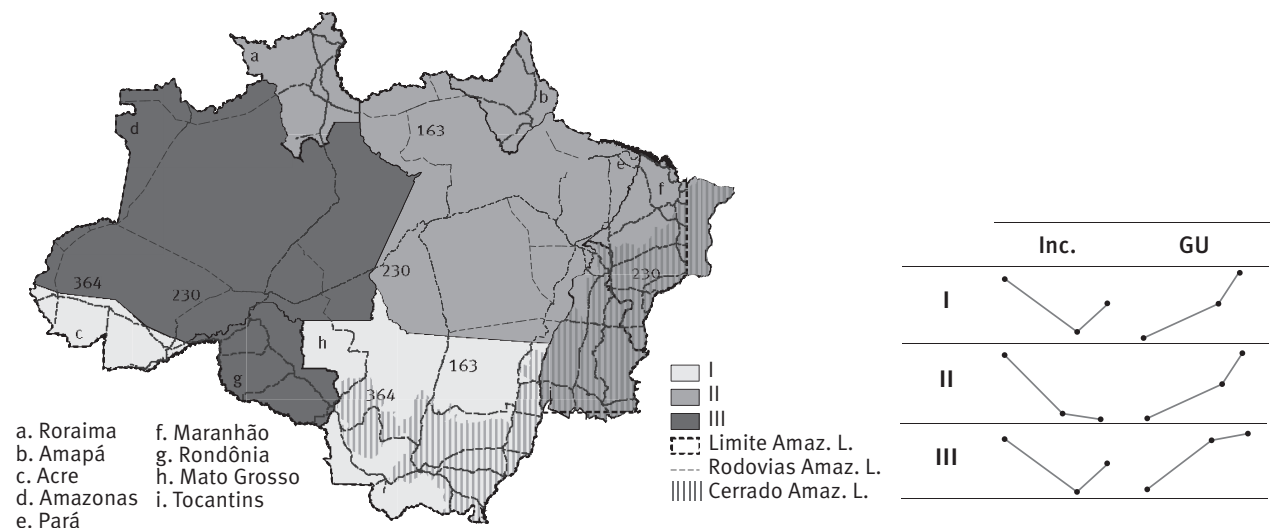

e. Pará
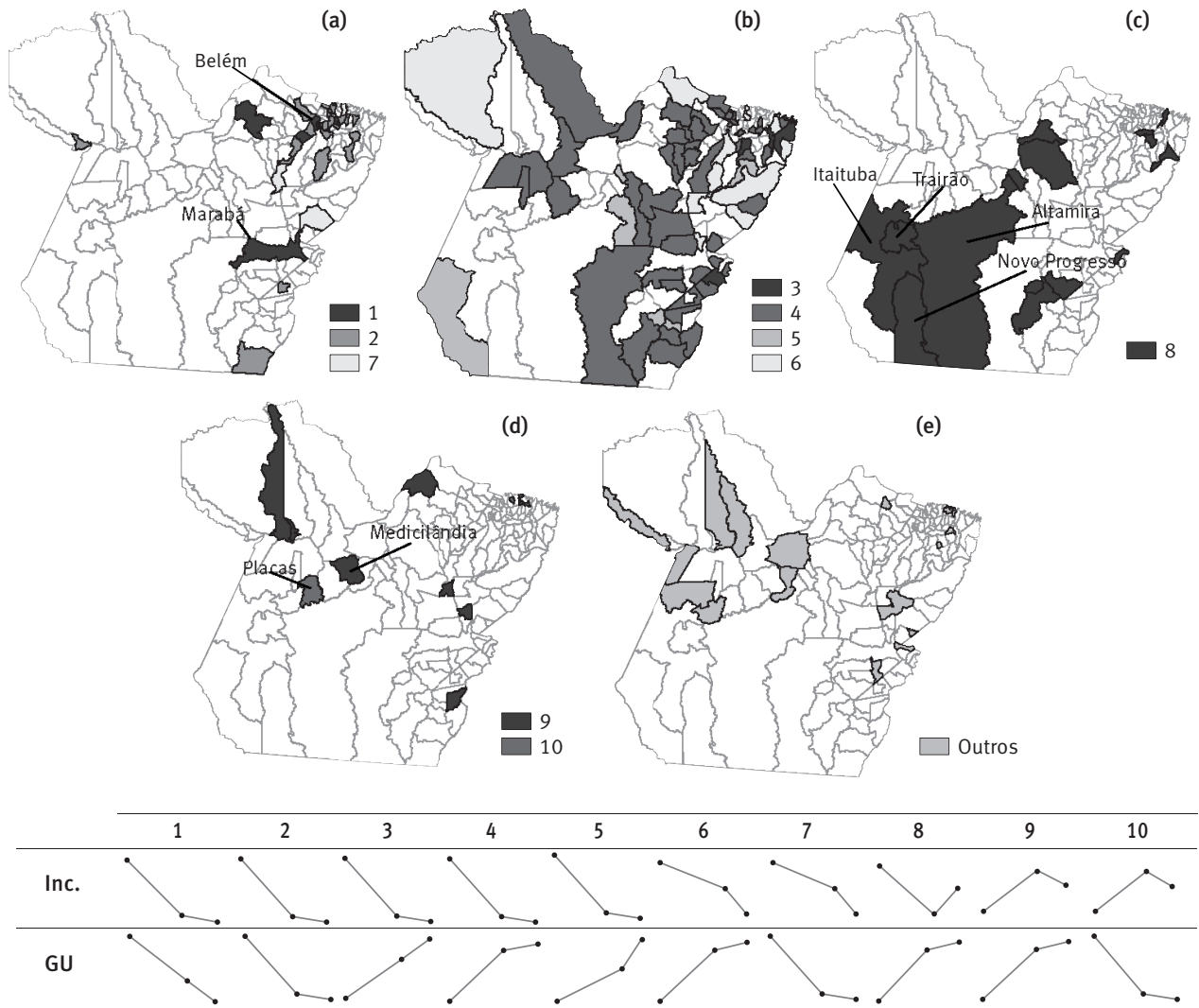

Fonte: IBGE (2000, 2010, 2014); Inpe (2015).

Municípios com: (a) dinâmica descendente de GU e desmatamento no período; (b) dinâmica descendente de desmatamento e ascendente de GU no período; (c) dinâmica ascendente e descendente (em formato "V" invertido") de desmatamento e dinâmica descendente de GU no período; (d) dinâmica descendente e ascendente do desmatamento (em formato de "V) e dinâmica ascendente (padrão 9) e descendente (padrão 10) de GU no período; (e) padrões não replicáveis da relação das dinâmicas de desmatamento e GU. 
Para as UFs, no grupo I encontram-se o Acre e o Mato Grosso, com dinâmicas de desmatamento e expansão urbana (GU) intensificadas após 2010 (Figura 3), reflexo da influência de fatores recentes no processo de ocupação territorial. Em que pesem as semelhanças, estes estados tiveram processos de exploração de recursos e ocupação distintos, principalmente em relação à expansão da fronteira agrícola. A implantação de grandes projetos agropecuários e garimpeiros no Mato Grosso respondem historicamente pelos altos níveis de desmatamento (SOARES-FILHO, 2001; RIVERO, 2009), enquanto o Acre teve suas atividades econômicas centradas no extrativismo (SOUZA, 2010). 0 principal elemento de similaridade histórica entre os dois estados foi a construção da Rodovia Brasília-Acre (BR-364) que, a partir de meados da década de 1970, promoveu a formação de povoados, vilas e cidades ao longo de seu eixo (SOUZA, 2010; PRATES; BACHA, 2011).

Ao padrão do grupo Il associam-se os estados do Pará, Maranhão, Roraima, Amapá e Tocantins, que apresentam redução do desmatamento, com maior variação entre 2000 e 2010 (Figura 3). O GU foi crescente em todo o período, com maior variação entre 2010 e 2014. Estes estados também sofreram diferentes processos históricos de ocupação territorial. Pará e Maranhão, por exemplo, situam-se em área de expansão da fronteira agrícola, com intensa atividade de desmatamento até o final da década de 1990 e redução a partir de 2000, decorrente da implantação de políticas de controle e fiscalização do desmatamento na Amazônia Legal (VALERIANO et al., 2012) - observada também nos demais estados da região. Além disso, a construção das principais rodovias (BR-230 e BR-163), que conectaram núcleos econômicos estratégicos, foi responsável por importantes mudanças na estrutura socioeconômica destes estados (BECKER, 2009).

Em contraponto, os processos de desmatamento do Amapá e Roraima são comandados prioritariamente por uma dinâmica regional endógena (BECKER, 2009). Assim como o estado do Amazonas, o Amapá e Roraima concentram unidades de conservação e terras indígenas (ISA, 2014) que atuam como fatores limitantes ao processo de conversão florestal. Quanto ao Tocantins, menos de $10 \%$ de sua área é coberta por floresta amazônica, e o desmatamento do cerrado, dominante no estado (Figura 3), foge ao escopo deste trabalho.

O padrão do grupo III inclui o Amazonas e Rondônia, que, apesar de geograficamente próximos, apresentam diferentes históricos de ocupação e dinâmicas de uso e cobertura. O Amazonas possui grande extensão territorial, alta concentração de áreas protegidas (ISA, 2014) e baixa conectividade com os eixos rodoviários de circulação. Estas características associadas tornam as atividades de desmatamento geralmente relacionadas às dinâmicas socioeconômicas locais. 0 crescimento populacional no Amazonas é atribuído basicamente à ocupação e circulação de Manaus (SCHOR; OLVEIRA, 2011): intenso processo migratório desde os anos 1960, incentivado pelas políticas de ocupação da Amazônia e criação da Zona Franca (NAZARETH et al., 2011). Por sua vez, Rondônia está entre os três estados que mais desmatam - depois do PA e MT (INPE, 2017). Rondônia recebeu grande parte dos fluxos migratórios durante os projetos de integração, a partir da década de 1970, e é 
considerado importante área de expansão das frentes comerciais e de atividade garimpeira (MATIAS-PEREIRA, 1997).

Nesta escala (Amazônia Legal), três características gerais foram observadas na dinâmica de evolução dos fenômenos: redução do desmatamento até 2010 e aumento em 2014; redução do desmatamento entre 2000 e 2014; e crescimento do GU entre 2000 e 2014 . A primeira e a segunda encontram-se associadas à implantação de políticas de comando e controle, responsáveis a partir dos anos 2000 pela contenção do desmatamento (BECKER, 2009; VALERIANO et al., 2012). Já o aumento observado em 2014 (grupos I e III) pode estar relacionado à expansão do setor imobiliário associado ao mercado de terras na Amazônia (COSTA, 2012, 2016; CARDOSO et al., 2016). A terceira característica, relacionada ao GU, pode ser explicada, primeiramente, pela tendência histórica nacional de concentração populacional em áreas urbanas (MATOS, 1995; BAENINGER, 1998; BRITO; SOUZA, 2005) e pelo o que Moura e Moreira (2001) definem como resultado da concentração de investimentos em espaços urbanos, que, além de atrair a população, estagna a economia no interior e gera fatores expulsivos para a população rural. Além das questões históricas que descrevem as dinâmicas de evolução da população na região, o conceito de urbanização extensiva (MONTE-MÓR, 1994, 2004) é uma forma de interpretar o aumento do GU no período mais recente. Em face da expansão do tecido urbano-industrial sobre áreas rurais, muitos espaços, antes considerados rurais, são oficialmente configurados como urbanos, com base nas definições estabelecidas pelo IBGE (2009).

Em nível municipal, da evolução das variáveis, identifica-se um padrão predominante representado por 35\% dos municípios (50 municípios): relação inversa entre os processos, ou seja, à medida que o grau de urbanização aumenta, na mesma intensidade, o incremento de desmatamento diminui (grupo 4) (Figura 3b) - semelhante ao observado no grupo II (que abrange o estado do Pará) para os dados agregados por UF. No entanto, a identificação de grupos com padrões distintos a este revela a importância de explorar as relações entre fenômenos tão complexos e heterogêneos quanto a expansão urbana e o desmatamento em diferentes escalas.

Nos padrões dos grupos 3, 4, 5 e 6 (Figura 3b), o desmatamento diminuiu ao longo de todo período, com redução mais acentuada entre 2000 e 2010, reflexo da implementação de políticas de controle do desmatamento a partir de 2004 (BECKER, 2009; VALERIANO et al., 2012). Por sua vez, o grupo 6 apresentou maior redução do desmatamento em período mais tardio - entre 2010 e 2014. Em relação ao GU, o grupo 3 registrou crescimento constante ao longo do período; os grupos 4 e 6 crescentes, com maior variação entre 2000 e 2010; e o grupo 5, também crescente, com maior intensidade entre 2010 e 2014.

Os padrões dos grupos 1, 2 e 7 (Figura 3a) referem-se aos municípios (29 municípios) com diminuição no incremento de desmatamento e GU no período. A maior redução do desmatamento ocorreu entre 2000 e 2010 (grupos 1 e 2), período também de maior variação para o GU nos grupos 2 e 7. No grupo 1, a redução do GU é constante no período. Se o desmatamento acompanhou as tendências gerais estaduais de redução, o GU apresenta 
relação inversa ao observado para o Pará (grupo II) e para a maioria dos municípios: redução da taxa ao longo do período analisado.

Espacialmente, os municípios dos grupos 1, 2 e 7 distribuem-se na porção leste do estado, com discreta concentração na região do nordeste paraense, próximo a Belém. Apesar de agregados, muitos municípios, como Belém, apresentam flutuações suaves no GU devido à saturação do índice. Isso ocorre em municípios onde a população se concentra integralmente, ou quase, em áreas urbanas, para os quais a interpretação deve ser relativizada. Alguns municípios destes grupos (1, 2 e 7) encontram-se sobre influência socioeconômica das dinâmicas da Região Metropolitana de Belém (RMB) (RIBEIRO, 2016) e outros fazem parte dela.

Em relação à dinâmica de desmatamento, os municípios dos grupos 1, 2 e 7, de modo geral, possuem poucos remanescentes florestais, como os da RMB (FERREIRA et al., 2012), ou recursos florestais restritos às áreas protegidas, como em Marabá. Desse modo, a redução no incremento do desmatamento ao longo da série temporal é explicada pela escassez de florestas primárias nestes municípios.

0 padrão do grupo 8 (14 municípios) (Figura 3c) exibe uma relação inversa entre as variáveis no primeiro período (2000-2010) - decréscimo de desmatamento e maior pico de crescimento da população urbana - e relação convergente no período seguinte (20102014), com crescimento de ambas as variáveis. Espacialmente há o agrupamento de alguns dos municípios (Itaituba, Novo Progresso, Trairão e Altamira) que se encontram, principalmente, às margens da Rodovia BR-163 (Cuiabá-Santarém). Nesta região, o processo de ocupação se deu, inicialmente, por projetos financiados pelo governo federal para abertura de novas estradas e exploração mineral. Em seguida, a expansão das frentes de ocupação, vista a redução da participação do poder público, passou a ser comandada por atores socioeconômicos regionais - pecuaristas, madeireiros e agricultores - instalados na região (BECKER, 2005). De modo geral, estes municípios apresentaram ao longo do tempo expressivo aumento populacional (ALVES et al., 2008) decorrente, principalmente, da expectativa de asfaltamento da rodovia, instalação de madeireiras e aquecimento do mercado de terras (ESCADA et al., 2009).

A redução do desmatamento entre 2000 e 2010 pode ser relacionada à estagnação da economia local, dependente da extração madeireira e impactada pela implantação de políticas de controle e fiscalização ambiental (ESCADA et al., 2009; VALERIANO et al., 2012). Contudo, mesmo com significativa concentração de áreas de proteção sob o domínio do governo federal na região sudoeste do Pará (18 Unidades de Conservação em 2014), o aumento da atividade de desmatamento a partir de 2010 pode estar relacionado à expansão recente das frentes agrícolas na região. Esta tendência de crescimento, principalmente a partir de 2014, é observada para o Pará e toda a Amazônia Legal, conforme levantamento anual do Prodes (INPE, 2017).

Os grupos 9 e 10 (Figura 3d) referem-se aos municípios (12) que apresentaram aumento do incremento de desmatamento até 2010 e redução em 2014, e GU com maior variação 
entre 2000 e 2010, porém com crescimento no grupo 9 e redução para o grupo 10. Esta dinâmica de desmatamento evidencia uma tendência contrária à observada para a maioria dos municípios do Pará e Amazônia Legal. São municípios com dinâmicas socioeconômicas particulares, como é o caso de Medicilândia (grupo 9) e Placas (grupo 10), que possuem suas origens associadas à Transamazônica e evolução do processo de ocupação baseado no desenvolvimento de atividades econômicas, tais como a produção de cacau e a pecuária, pela própria dinâmica da rodovia e evolução dos projetos de assentamentos (NAEA, 2009; CARDOSO; LIMA, 2009; NEVES et al., 2014).

O grupo "outros" contém municípios que apresentaram padrões únicos, ou tendências não recorrentes em mais de três municípios, de evolução do incremento de desmatamento e grau de urbanização. Os resultados ressaltam que os processos de conversão florestal e urbanização mostram múltiplas tendências de evolução que traduzem suas complexidades nas análises espaço-temporais.

\section{Parte 2 - Evidências de singularidades locais}

Os resultados globais de ajuste geral das variáveis no modelo GWR para a resolução municipal (Tabela 1 ) mostram que para ambos os modelos, de área urbana (Log ( $\triangle$ Área Urbana $)=f \log (\Delta$ Desmat. Acum. $))$ e de população urbana (Log $(\Delta$ Pop. Urbana $)=f$ Log $(\Delta$ Desmat. Acum.)), o coeficiente de determinação atingiu valores pouco significativos. 0 desmatamento mostrou-se relacionado a apenas $36 \%$ da dinâmica de população urbana e $40 \%$ da dinâmica de expansão de áreas urbanas, na escala municipal. Destes 36\%, 29 municípios (20\% do total) são significativos para o modelo de população urbana e, dos $40 \%, 65$ municípios (45\% do total) são significativos para o modelo de área urbana. Este resultado indica que, de modo geral, mesmo considerando as relações espaciais, a dinâmica de expansão urbana no território paraense não está diretamente relacionada aos processos de desmatamento. Tanto o $\mathrm{R}^{2}$ ajustado como o valor de Akaike indicam que 0 modelo de área urbana apresenta um ajuste melhor em relação à variável independente $(\log (\Delta$ Desmat. Acum.)) para esta unidade de análise (Tabela 1).

TABELA 1

Principais resultados dos modelos de regressão espacial local para a resolução municipal

\begin{tabular}{lcc}
\hline \multicolumn{1}{c}{ Variáveis } & $\log (\boldsymbol{\Delta}$ Área Urb. $) \boldsymbol{f} \log (\boldsymbol{\Delta}$ Desmat. Acum. $)$ & $\begin{array}{c}\text { Log }(\boldsymbol{\Delta} \text { Pop. Urb. })=\boldsymbol{f} \text { Log }(\boldsymbol{\Delta} \text { Desmat. } \\
\text { Acum. })\end{array}$ \\
\hline R2 Ajust. & 0,40 & 0,36 \\
Akaike & 129,50 & 212,27 \\
a (mediana) & 0,15 & 3,24 \\
B (mediana) & 0,23 & 0,15 \\
\hline
\end{tabular}

Fonte: Almeida et al. (2016); IBGE (2000, 2014); Inpe (2015).

Os coeficientes angulares obtidos do modelo de área urbana apresentaram valores positivos, mas com variadas intensidades, delineando padrões espaciais que demonstram a variação da contribuição da variável independente sobre a variável dependente (Figura 
4c). 0 intercepto ${ }^{2}$ não teve significância em quase toda a área de estudo, significando que, majoritariamente, quando o desmatamento acumulado (Log ( $\Delta$ Desmat. Acum.)) é igual a 0 (zero) na área de estudo, a área urbana (Log ( $\Delta$ Área Urbana)) não é significativamente diferente de 0 (zero) (Figura 4d).

Toda área mapeada ${ }^{3}$ pelo modelo é dividida em dois polos (leste-oeste) com coeficientes angulares positivos em diferentes intensidades, com exceção da parte norte da Mesorregião Sudeste, que abrange Marabá e alguns municípios do entorno, e da parte noroeste da Mesorregião do Baixo Amazonas. Estes dois grupos de municípios apresentaram valores atípicos em relação a seus vizinhos (Figura 4c).

No que se refere ao modelo de população urbana, os coeficientes angulares apresentaram valores positivos e negativos, demonstrando diferentes formas de co-ocorrência das variáveis ao se considerarem as relações espaciais como dimensão de análise (Figura 4g). Neste modelo, o intercepto é significativo em toda a área de estudo, o que indica que, quando o desmatamento acumulado (Log ( $\Delta$ Desmat. Acum.)) é igual a 0 (zero), a dinâmica de população urbana (Log ( $\Delta$ Pop. Urbana)) na área de estudo é, em sua totalidade, diferente de 0 (zero) (Figura 4h).

Entre os resultados obtidos, o extremo norte da Mesorregião do Sudeste Paraense, abrangendo o município de Marabá e entorno, se destaca, assim como no modelo anterior, por apresentar os maiores valores de coeficientes angular e de determinação da área de estudo. Isso pode estar refletindo um efeito de vizinhança, causado pela significativa variação de área urbana, população urbana e desmatamento de Marabá (Figura 2), ou por apresentar baixos valores em ambas as variáveis.

Os municípios significativos localizados na RMB apresentam coeficientes com valores negativos, delineando relação inversa entre a população urbana e o desmatamento acumulado. Esta região apresenta alta concentração populacional e baixos valores de desmatamento no período.

O município de São Felix do Xingu registrou dinâmicas ativas de evolução de população urbana e desmatamento acumulado entre 2000 e 2014 (Figura 2) e médios coeficientes de determinação e angular (Figura $4 \mathrm{f}-\mathrm{g}$ ). Por outro lado, Novo Progresso obteve semelhantes valores de coeficientes de determinação e angular (Figura $4 \mathrm{f}-\mathrm{g}$ ), mas apresenta a variação do desmatamento acumulado muito maior do que a de população urbana (Figura 2). As diferentes dinâmicas de evolução das variáveis e semelhante resultado na GWR demonstram a influência do espaço na relação entre o desmatamento e a expansão urbana.

\footnotetext{
2 Valor da variável dependente quando a variável independente é igual a zero.

3 Estatisticamente significante a 95\% de confiança (+/- 1,96 - estatística t).
} 
Assim como para os municípios, os resultados globais de ajuste geral das variáveis dos modelos GWR na resolução celular (Tabela 2 ) apresentaram valores baixos de coeficientes de determinação, indicando que também para unidades mais finas a influência do desmatamento sobre a dinâmica de expansão urbana é pequena. 0 desmatamento mostrou-se relacionado a cerca de $17 \%$ da dinâmica de população urbana e $16 \%$ da dinâmica de expansão de área urbana. Destas porcentagens, $26 \%$ das unidades válidas são significativas para o modelo de população urbana e 33\% são significativas para o modelo de área urbana. Os valores de $\mathrm{R}^{2}$ ajustado e Akaike indicam que o modelo de população urbana apresenta um ajuste melhor em relação à variável independente (Log $(\Delta$ Desmat. Acum.)) para esta unidade de análise (Tabela 2).

FIGURA 4

Resultados dos modelos GWR entre as variáveis de expansão urbana e desmatamento na resolução municipal do Estado do Pará
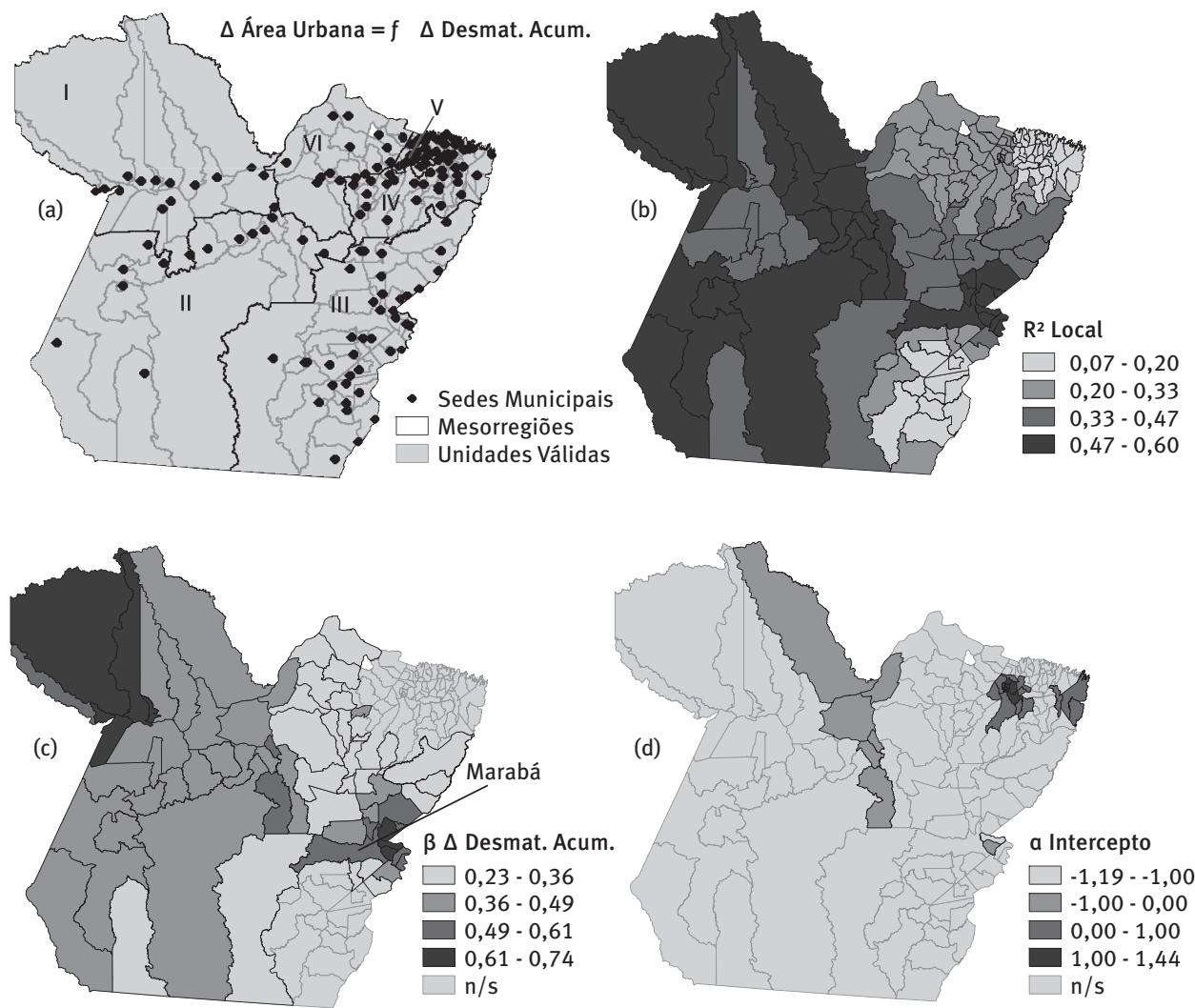

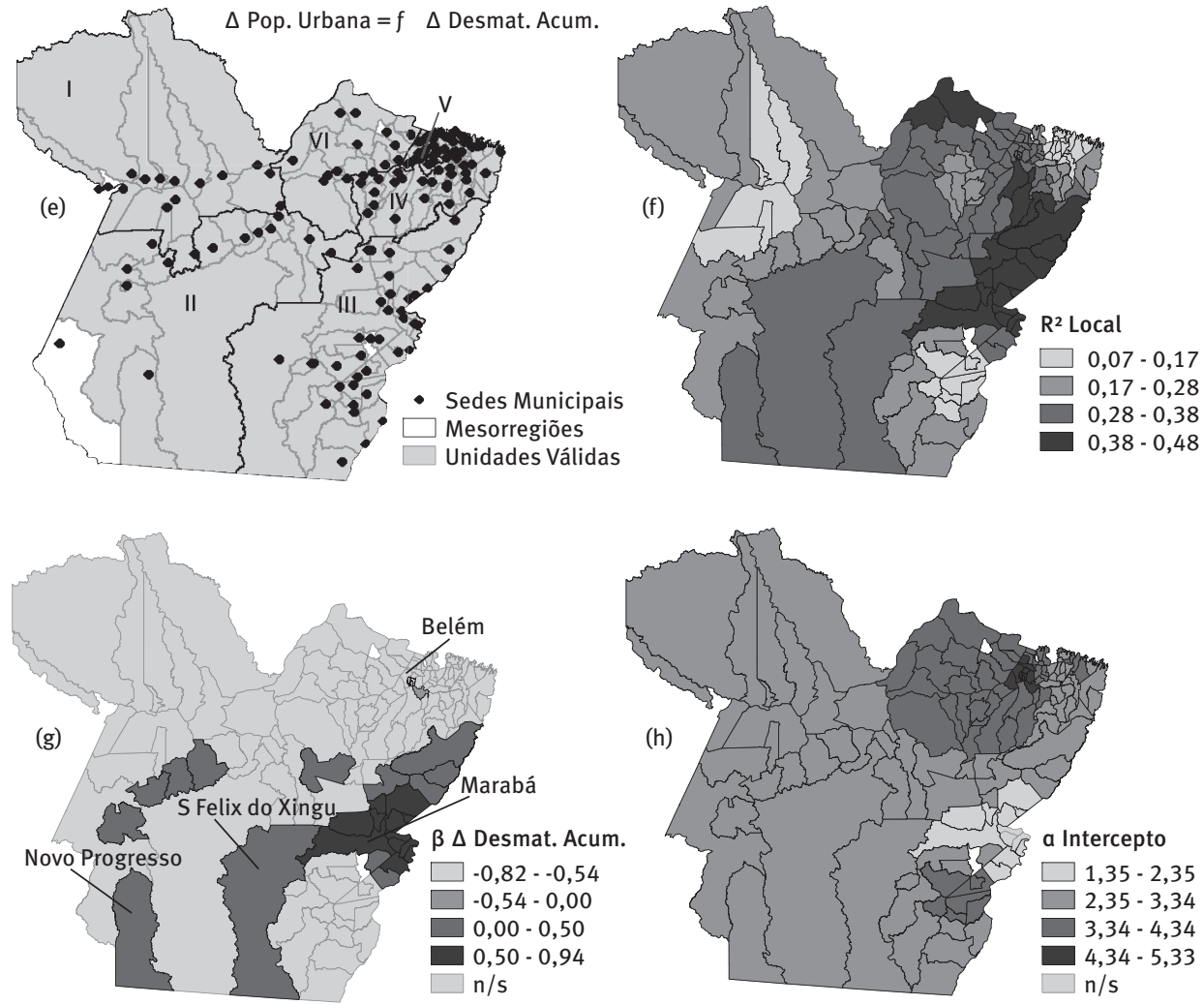

Fonte: Almeida et al. (2016); IBGE (2000, 2014); Inpe (2015).

(a) Conjunto amostral - sedes municipais: I - Mesorregião do Baixo Amazonas; II - Mesorregião do Sudoeste Paraense; III - Mesorregião do Sudeste Paraense; IV - Mesorregião do Nordeste Paraense; V - Mesorregião Metropolitana de Belém; VI Mesorregião do Marajó; (b) R² local; (c) Coeficiente angular; (d) Intercepto; n/s - não significativo.

TABELA 2

Principais resultados dos modelos de regressão espacial local para a resolução celular

\begin{tabular}{lcc}
\hline \multicolumn{1}{c}{ Variáveis } & Log $(\boldsymbol{\Delta}$ Área Urb. $) \boldsymbol{=} \boldsymbol{f} \log (\boldsymbol{\Delta}$ Desmat. Acum.) & $\log (\boldsymbol{\Delta}$ Pop. Urb. $)=\boldsymbol{f}$ Log $(\boldsymbol{\Delta}$ Desmat. Acum. $)$ \\
\hline R2 Ajust. & 0,16 & 0,17 \\
Akaike & 1251,38 & 428,38 \\
a (mediana) & $-0,33$ & 3,12 \\
B (mediana) & 0,14 & 0,18 \\
\hline
\end{tabular}

Fonte: Almeida et al. (2016); IBGE (2000, 2014); Inpe (2015).

O modelo de área urbana destaca duas principais áreas pelos valores mais significativos do coeficiente angular, ou seja, áreas onde a dinâmica do desmatamento é mais relacionada com a dinâmica de expansão urbana, medida pela área urbana. Essas áreas estão localizadas na Região Metropolitana de Belém (RMB) e na parte sul de Itaituba. A RMB apresenta células com valores médios-altos de variação de área urbana no período e baixos valores de variação do desmatamento acumulado (Figura 2). De modo semelhante, Itaituba registrou desmatamento ativo, principalmente na porção sul do 
município, e baixos valores de variação de área urbana (Figura 2). Assim, os valores dos parâmetros não correspondem ao esperado e refletem a contribuição do espaço na análise da relação entre as variáveis (Figura $5 \mathrm{c}$ ). Deve-se destacar que na resolução municipal a RMB foi considerada não significativa em ambos os modelos espaciais, mostrando que a estrutura espacial da relação das variáveis encontra-se condicionada ao recorte territorial estabelecido.

Outro destaque foram as células localizadas no município de Novo Progresso, que apresentaram coeficiente angular e de determinação com valores médios a altos (Figura $5 b-c)$. 0 resultado dos parâmetros conseguiu refletir o esperado uma vez que, para as áreas onde as células estão localizadas no município, tanto o desmatamento acumulado quanto a variação de área urbana apresentaram valores baixos no período (Figura 2). Os valores dos coeficientes de determinação variaram entre 0,01 e 0,22. Este resultado indica que, mesmo presente, de modo geral nesta escala, o desmatamento (Log $(\Delta$ Desmat. Acum.)) mostrou-se pouco relacionado com a dinâmica de área urbana (Log $(\Delta$ Área. Urbana)) (Figura 5b).

FIGURA 5

Resultados dos modelos GWR entre as variáveis de expansão urbana e desmatamento na resolução celular do Estado do Pará
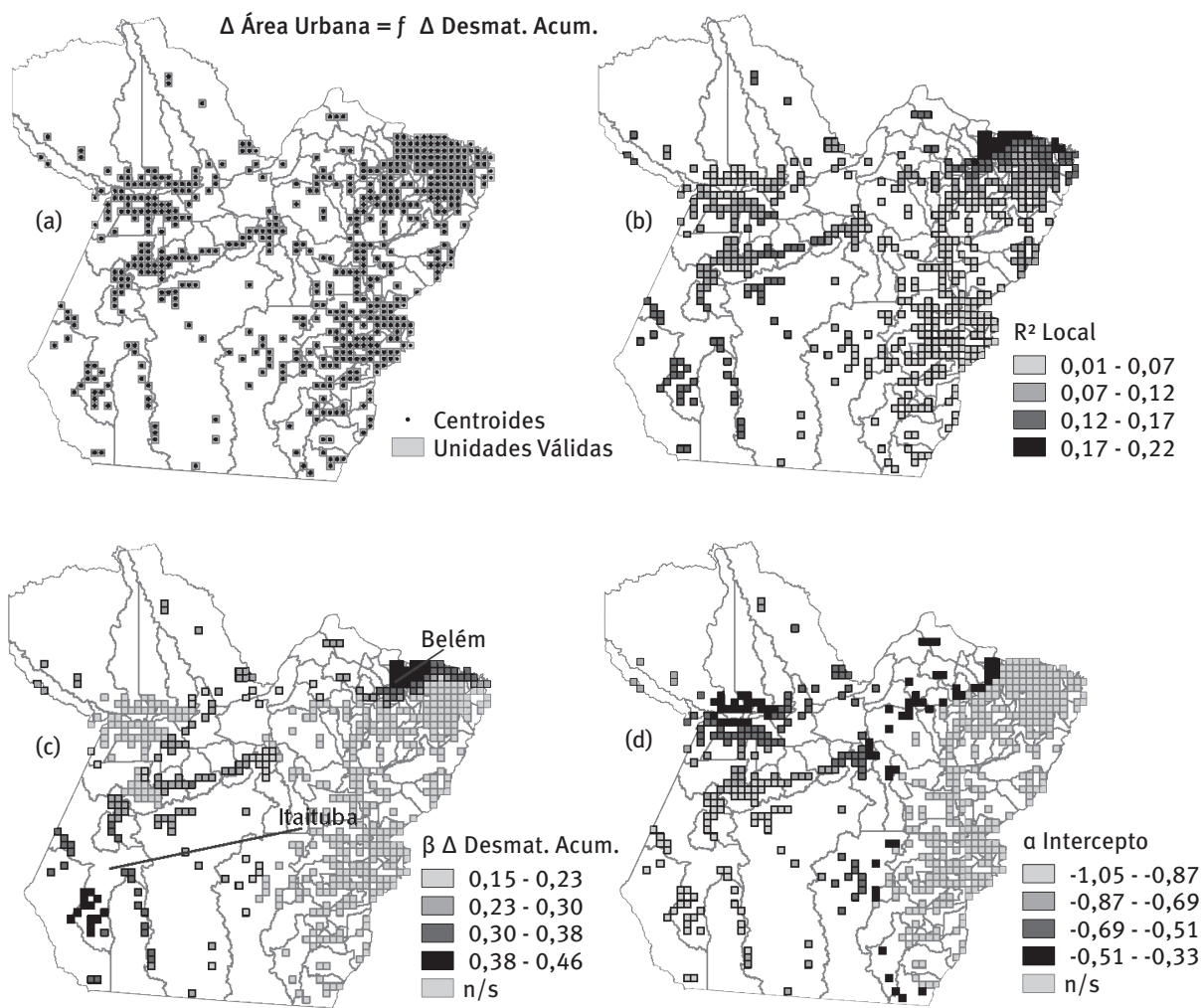

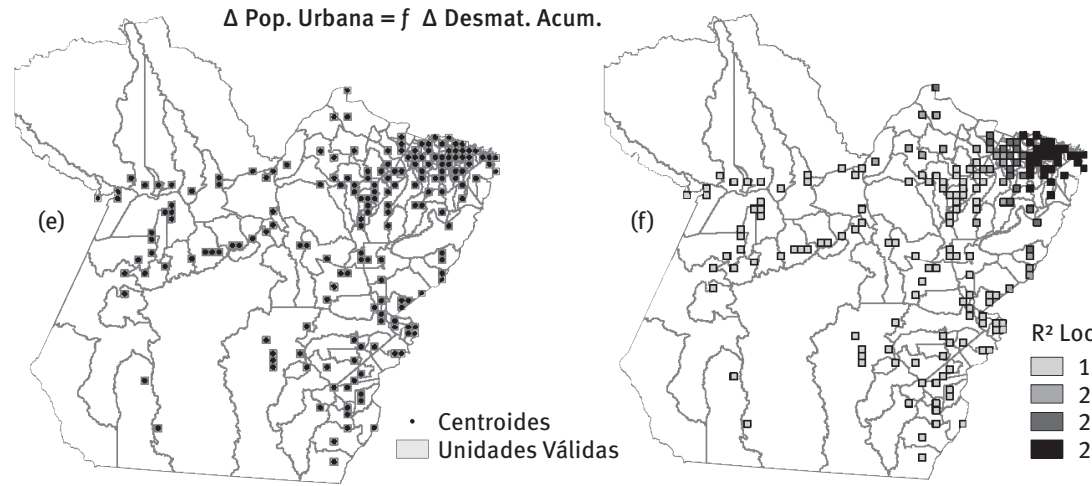

(e)

(f)
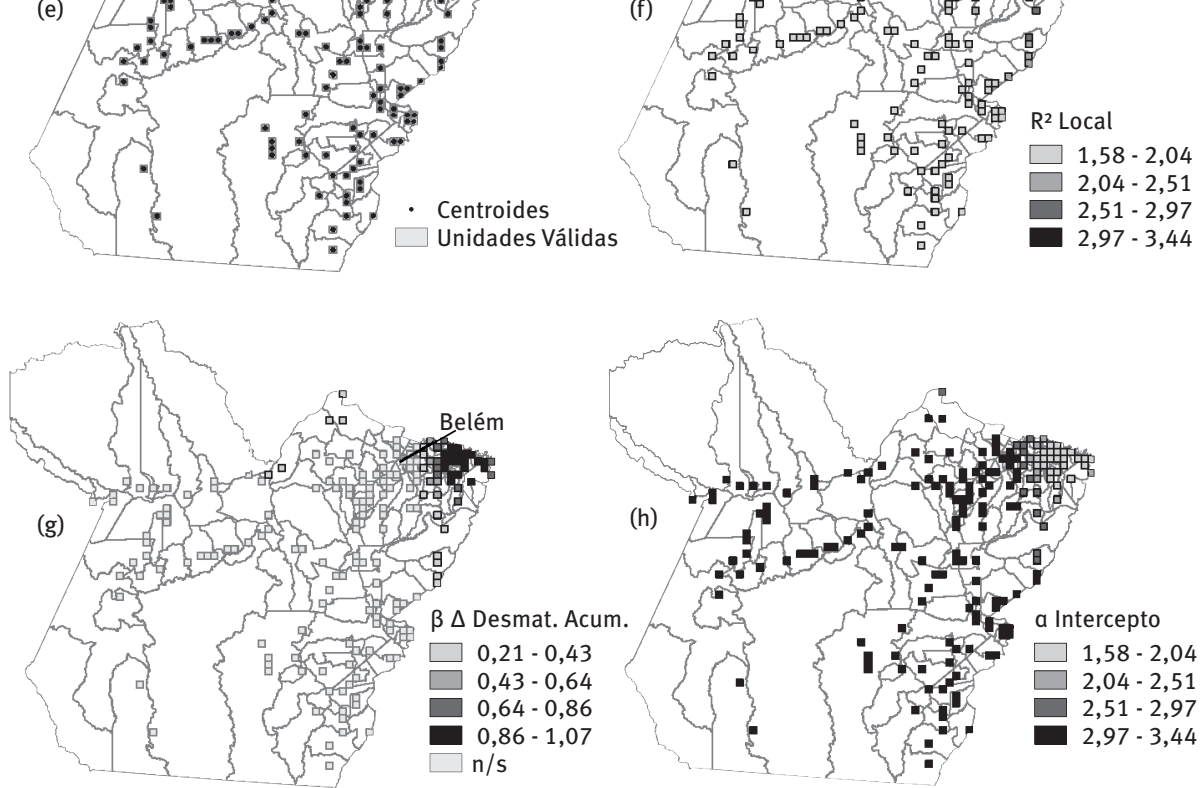

Fonte: Almeida et al. (2016); IBGE (2000, 2014); Inpe (2015).

(a) Conjunto amostral - sedes municipais: I - Mesorregião do Baixo Amazonas; II - Mesorregião do Sudoeste Paraense; III - Mesorregião do Sudeste Paraense; IV - Mesorregião do Nordeste Paraense; V - Mesorregião Metropolitana de Belém; VI Mesorregião do Marajó; (b) R² local; (c) Coeficiente angular; (d) Intercepto; n/s - não significativo.

Em relação ao modelo de população urbana, destaca-se um grupo de células no nordeste paraense, principalmente na RMB. Esta região pouco se destaca do contexto geral quanto à variação da população urbana (Figura 2), com exceção das células referentes a Belém e Ananindeua, que se mantêm com altos valores de população urbana ao longo dos anos. De forma análoga, por se tratar de uma área intensamente desmatada no passado e com poucos remanescentes florestais, a variação do desmatamento acumulado é diminuta (Figura 2). Estas características particulares respondem ao destaque desta região nos resultados dos parâmetros da GWR (Figura 5g). Para o coeficiente de determinação, os valores variaram entre 0,03 e 0,37. Estes resultados indicam que, ainda que presente, de modo geral nesta escala, o desmatamento (Log ( $\Delta$ Desmat. Acum.)) mostrou-se pouco relacionado com a dinâmica de população urbana (Log ( $\Delta$ Pop. Urbana)) (Figura $5 f)$. 


\section{Considerações finais}

Os diferentes padrões de evolução das variáveis de conversão florestal e urbanização evidenciaram as particularidades regionais e ressaltaram a importância do recorte espaço-temporal para interpretação da realidade amazônica. Destaca-se que os resultados observados neste trabalho são representações reduzidas de processos muito mais complexos, que envolvem fatores e agentes operando em diferentes níveis e escalas e, com isso, não há a pretensão de estabelecer relações conclusivas ou de causalidade, mas sim destacar a diversidade de formas de co-ocorrência dos dois processos em análise.

Para os nove estados da Amazônia Legal e os 143 municípios do Pará, a evolução dos processos de conversão florestal e urbanização, mediados pelo desmatamento e expansão urbana, apresentou diferentes comportamentos. Os padrões de evolução do incremento de desmatamento e grau de urbanização discriminaram três grupos nas unidades estaduais para a Amazônia Legal e 11 grupos nas unidades municipais para o estado do Pará. Estas diferenças destacam a variedade de formas de co-ocorrência ou concordância destes processos e mostram que, mesmo inseridos em contextos histórico-geográficos semelhantes, há fatores e agentes diversos atuando nas dinâmicas de urbanização e conversão florestal, resultando em respostas heterogêneas na evolução das variáveis, que não podem ser reduzidas a uma única escala de análise, assim como a uma única causa ou fator.

A análise de associação espacial da urbanização e conversão florestal mostrou que ambos os modelos, considerando a relação de desmatamento com área urbana ou população urbana, apresentaram baixos valores de coeficiente de determinação. Em suma, tanto os modelos globais (não espaciais) quanto os locais (espaciais) apontaram a falta de sincronia entre o desmatamento e a evolução da área urbana e o desmatamento e a evolução da população urbana. Isto revela que a relação entre a urbanização e a conversão florestal assume diversas formas e intensidades ao longo do espaço e do tempo.

Na resolução municipal, mesmo entre municípios contíguos e com semelhanças em seus históricos de ocupação, as distintas dinâmicas mais recentes (2000 a 2014) de desmatamento e expansão urbana resultaram em relações não significativas de associação espacial. Na resolução celular, ao se analisarem unidades espaciais dissociadas de limites político-administrativos, observou-se a descontinuidade espacial dos processos de desmatamento e expansão urbana, que, apesar de concomitantes, ocorrem em diferentes lugares dentro do limite municipal. Estas diferenças espaciais reforçam a compreensão desta relação como indireta e não causal. Além disso, comparando os resultados das regressões espaciais, as diferenças nas estruturas de associação espacial entre os municípios e células indicam que os processos interagem de formas distintas conforme a mudança de unidade de análise.

Os diferentes padrões de evolução e agrupamentos das unidades territoriais, resultantes das duas etapas metodológicas (análise de tendências e regressões espaciais) mostraram que a relação urbanização-conversão florestal, mediada por seus elementos 
observáveis desmatamento e expansão urbana, foi sensível à escala, unidade de análise, abordagem metodológica e dados mediadores. Assim, ressalta-se a importância de adequar os recortes metodológicos ao se buscar interpretar quanti-qualitativamente a interação entre processos que dependem de diversos agentes e fatores. Estes apontamentos enriquecem a discussão sobre a heterogeneidade da relação entre a urbanização e a conversão florestal na Amazônia e permitem afirmar que os processos de urbanização e aqueles de conversão florestal evoluem de formas distintas, certamente interligados, mas em graus e intensidades que se revelam ao longo do tempo, do espaço e das escalas de observação.

\section{Referências}

AB'SABER, A. Zoneamento ecológico e econômico da Amazônia: questões de escala e método. Estudos Avançados, v. 3, n. 5, p. 4-20, 1989.

ALMEIDA, C. A. de et al. High spatial resolution land use and land cover mapping of the Brazilian Legal Amazon in 2008 using Landsat-5/TM and MODIS data. Acta Amazonica, v. 46, n. 3, p. 291-302, 2016.

ALVES, P. A.; AMARAL, S.; ESCADA, M. I. S.; MONTEIRO, A. M. V. Explorando as relações entre a dinâmica demográfica, estrutura econômica e mudanças no uso e cobertura da terra no sul do Pará: lições para o Distrito Florestal Sustentável da BR-163. Geografia, v. 35, n. 1, p. 165-182, 2010.

AMARAL, S. et al. Using remote sensing and census tract data to improve representation of population spatial distribution: case studies in the Brazilian Amazon. Population and Environment, v. 34, n. 1, p. 142-170, 2012.

AMARAL, S. Geoinformação para estudos demográficos: representação espacial de dados de população na Amazônia Brasileira. Tese (Doutorado em Engenharia de Transporte) - Escola Politécnica da Universidade de São Paulo, São Paulo, 2003.

AMARAL, S.; CAMARA, G.; MONTEIRO, A. M. V. Configurações espaciais do processo de desflorestamento da Amazônia. São José dos Campos: Inpe, 2001.

ANSELIN, L. Local indicators of spatial association - LISA. Geographical Analysis, v. 27, n. 2, p. 93-115, 1995.

BAENINGER, R. A nova configuração urbana no Brasil: desaceleração metropolitana e redistribuição da população. In: XI ENCONTRO NACIONAL DE ESTUDOS POPULACIONAIS. Anais... Caxambu, MG: Abep, 1998.

BARBIERI, A. F. Mobilidade populacional e meio ambiente em áreas de fronteira: uma abordagem multi-escalar. Revista Brasileira de Estudos de População, v. 24, n. 2, p. 225-246, 2007.

BAUMONT, C. Spatial effects in housing price models. Do housing prices capitalize urban development policies in the agglomeration of Dijon (1999)? Universite de Bourgogne, LEG Laboratoire d'Economie et de Gestion, 2004. (Document de travail - Economie 2004-04).

BECKER, B. K. Amazônia: geopolítica na virada do III milênio. 4. ed. Rio de Janeiro: Garamond, 2009.

Geopolítica da Amazônia. Estudos Avançados, v. 19, n. 53, p. 71-86, 2005.

Revisão das políticas de ocupação da Amazônia: é possível identificar modelos para

projetar cenários? Parcerias Estratégicas, v. 6, n. 12, p. 135-159, 2001. 
A urbe amazônida. 1. ed. Rio de Janeiro: Garamond, 2013.

BECKER, B. K.; EGLER, C. Detalhamento da metodologia para execução do zoneamento ecológico-econômico pelos Estados da Amazônia Legal. Brasília: Ministério do Meio Ambiente, 1997.

BECKER, B. K.; STENNER, C. Um futuro para a Amazônia. 3. ed. São Paulo: Oficina de Textos, 2008.

BRASIL. Ministério do Meio Ambiente. Biomas brasileiros. Brasília, 2009. Disponível em: «http:// www.brasil.gov.br/meio-ambiente/2009/10/biomas-brasileiros〉. Acesso em: 09 maio 2017.

Malha digital Brasil. Brasília, 2010. Disponível em: 〈http://mapas.mma.gov.br/ i3geo/datadownload.htm>. Acesso em: 24 mar. 2018.

BRITO, F.; SOUZA, J. de. Expansão urbana nas grandes metrópoles: o significado das migrações intrametropolitanas e da mobilidade pendular na reprodução da pobreza. São Paulo em Perspectiva, v. 19, n. 4, p. 48-63, 2005.

BRUNSDON, C.; FOTHERINGHAM, A. S.; CHARLTON, M. E. Geographically weighted regression: a method for exploring spatial nonstationarity. Geographical Analysis, v. 28, n. 4, p. 281-298, 1996.

CARDOSO, A. C. D.; LIMA, J. J. F. A influência do governo federal sobre cidades na Amazônia: os casos de Marabá e Medicilândia. Novos Cadernos NAEA, v. 12, n. 1, p. 161-192, 2009.

CARDOSO, A. C. D.; MELO, A. C. C.; GOMES, T. do V. O urbano contemporâneo na fronteira de expansão do capital: padrões de transformações espaciais em seis cidades do Pará, Brasil. Revista de Morfologia Urbana. v. 4, n. 1, p. 5-28, 2016.

CARDOSO, A. C. D.; NEGRÃO, M. R. G. Das máquinas autoritárias de planejamento do século XX, às máquinas de crescimento urbano do século XXI: o caso do sudoeste do Pará. In: ENCONTRO NACIONAL DA ASSOCIAÇÃO NACIONAL DE PÓS-GRADUAÇÃO E PESQUISA EM PLANEJAMENTO URBANO E REGIONAL - ENANPUR, 15. Anais... Recife: RBEUR, 2013.

CARR, D. L. Proximate population factors and deforestation in tropical agricultural frontiers. Population and Environment, v. 25, n. 6, p. 585-612, 2004.

CARVALHO, M. S.; CÂMARA, G.; CRUZ, O. G.; CORREA, V. Análise de dados de área. In: DRUCK, S.; CARVALHO, M. S.; CÂMARA, G.; MONTEIRO, A. V. M. (Ed.). Análise espacial de dados geográficos. Brasília, Embrapa, 2004.

COSTA, F. A. Contributions of fallow lands in the Brazilian Amazon to $\mathrm{CO} 2$ balance, deforestation and the agrarian economy: inequalities among competing land use trajectories. Elementa: Science of the Anthropocene, v. 4, p. 1-24, 2016.

Mercado de terras e trajetórias tecnológicas na Amazônia. Economia e Sociedade, v. 21, n. 2, p. 245-273, 2012.

CROPPER, M.; GRIFFITHS, C. The interaction of population growth and environmental quality. The American Economic Review, v. 84, n. 2, p. 250-254, 1994.

DAL'ASTA, A. P.; AMARAL, S.; SOARES, F. R.; MONTEIRO, A. M. V. Evolução recente da população urbana comparada à evolução do desmatamento nos municípios do distrito florestal sustentável da BR-163. In: XVIII ENCONTRO NACIONAL DE ESTUDOS POPULACIONAIS. Anais... São Paulo: Abep, 2012.

ESCADA, M. I. S.; AMARAL, S.; RENNÓ, C. D.; PINHEIRO, T. F. Levantamento do uso e cobertura da terra e da rede de infra-estrutura no distrito florestal da BR-163. São José dos Campos: Inpe, 2009. (INPE-15739-RPQ/824). Disponível em: ‘http://urlib.net/8JMKD3MGP8W/357DD7L〉. Acesso em: 24 fev. 2017.

FAPESPA - Fundação Amazônia de Amparo a Estudos e Pesquisas do Pará; MOREIRA, M. G. Estimativas e projeções do PIB paraense 2014-2020. Belém: Fapespa, 2016. 
Estimativas e projeções do PIB paraense 2015-2020. Belém, 2017.

FEITOSA, F. F.; MONTEIRO, A. M. V. Vulnerabilidade e modelos de simulação como estratégias mediadoras: contribuição ao debate das mudanças climáticas e ambientais. Geografia, v. 37, n. 2, p. 289-305, 2012.

FERREIRA, L. V.; PAROLIN, P.; MUÑOZ, S. H.; CHAVES, P. P. O efeito da fragmentação e isolamento florestal das áreas verdes da região metropolitana de Belém. Pesquisas, Botânica, n. 63, p. 357-367, 2012.

FERREIRA, L. V.; VENTICINQUE, E.; ALMEIDA, S. O desmatamento na Amazônia e a importância de áreas protegidas. Estudos Avançados, n. 19, p. 157-166, 2005.

GIBSON, C.; OSTROM, E.; AHN, T. K. The concept of scale and the human dimensions of global change. Ecological Economics, v. 32, n. 2, p. 217-239, 2000.

GREIG, D. M. Optimisation. Longman Publishing Group, 1980.

HOGAN, D. J.; D'ANTONA, A. de O.; CARMO, R. L. Dinâmica demográfica recente da Amazônia. In: BATISTELLA, M.; MORAN, E. F.; ALVES, D. S. (Org.). Amazônia: natureza e sociedade em transformação. São Paulo: Editora da Universidade de São Paulo, 2008. p. 71-116.

IBGE - Instituto Brasileiro de Geografia e Estatística. Censo Demográfico 2000. Rio de Janeiro, 2000. Disponível em: 〈http://www.ibge.gov.br/home/estatistica/populacao/censo2000/〉. Acesso em: 02 mar. 2017.

. América do Sul. Rio de Janeiro, 2000b. Disponível em: 〈https://downloads.ibge. gov.br/downloads_geociencias.htm>. Acesso em: 24 mar. 2018.

Censo Demográfico 2010. Rio de Janeiro, 2010. Disponível em: 〈http://censo2010. ibge.gov.br/>. Acesso em: 02 mar. 2017.

Dados de população e situação de domicílio. Rio de Janeiro, 2010a. Disponível em: 〈http://www.cens02010.ibge.gov.br/sinopse/index.php?dados=8〉. Acesso em: 05 mar. 2017.

Dados populacionais do estado do Pará 2000 e 2010. Rio de Janeiro, 2010b. Disponivel em: 〈http://www.ibge.gov.br/estadosat/perfil.php?sigla=pa〉. Acesso em: 15 fev. 2017.

Sinopse do Censo Demográfico 2010. Rio de Janeiro, 2010c. Disponível em: «https:// cens02010.ibge.gov.br/sinopse/index.php?dados=8>. Acesso em: 12 jul. 2018.

Malha digital Pará. Rio de Janeiro, 2010d. Disponível em: 〈https://downloads.ibge. gov.br/downloads_geociencias.htm>. Acesso em: 12 jul. 2018.

Síntese de Notas Técnicas. Rio de Janeiro, 2009. Disponível em: 〈http://www.ibge. gov.br/home/estatistica/populacao/trabalhoerendimento/pnad2009/sintese_notas_tecnicas. pdf〉. Acesso em: 03 mar. 2017.

Estimativa populacional 2014. Rio de Janeiro, 2014. Disponível em: 〈http://www. ibge.gov.br/home/estatistica/populacao/estimativa2014/default.shtm>. Acesso em: 06 de março de 2017.

INPE - Instituto Nacional de Pesquisas Espaciais; CÂMARA, G.; VALERIANO, D.; VIANEI, J. Metodologia para o cálculo da taxa anual de desmatamento na Amazônia Legal. 3. ed. São José dos Campos: Inpe, 2006. Disponível em: 〈http://www.obt.inpe.br/prodes/metodologia_ TaxaProdes.pdf.> Acesso em: 20 fev. 2017.

Dados por município PRODES. São José dos Campos, 2015. Disponível em: 〈http:// www.dpi.inpe.br/prodesdigital/prodesmunicipal.php〉. Acesso em: 16 jun. 2017.

Taxa de desmatamento Amazônia Legal. São José dos Campos, 2017. Disponível em: 〈http://www.obt.inpe.br/prodes/dashboard/prodes-rates.html〉. Acesso em: 10 jun. 2018. 
. TerraClass 2004. São José dos Campos, 2004. Disponível em: 〈http://www.inpe.br/ cra/projetos_pesquisas/terraclass2004.php〉. Acesso em: 06 mar. 2017.

TerraClass 2014. São José dos Campos, 2014. Disponivel em: 〈http://www.inpe.br/ cra/projetos_pesquisas/terraclass2014.php〉. Acesso em: 06 mar. 2017.

ISA - Instituto Socioambiental. Programa de Monitoramento de Áreas Protegidas - unidades da federação. 2014. Disponível em <https://uc.socioambiental.org/c\%C3\%B4mputos/ amaz\%C3\%B4nia-legal/unidades-da-federa\%C3\%A7\%C3\%A30〉. Acesso em: 02 jul. 2017.

KIRBY, K. R. et al. The future of deforestation in the Brazilian Amazon. Futures, v. 38, n. 4 , p. 432-453, 2006.

LANGFORD, M.; UNWIN, D. J. Generating and mapping population density surfaces within a geographical information system. The Cartographic Journal, v. 31, p. 21-26, 1994.

MADEIRA, J. L.; SIMÕES, C. C. Estimativas preliminares da população urbana e rural segundo as unidades da federação de 1960/1980 por uma nova metodologia. Revista Brasileira de Estatística, v. 33, n. 129, p. 3-11, 1972.

MARGULIS, S. Quem são os agentes dos desmatamentos na Amazônia e por que eles desmatam. Brasília: Banco Mundial, 2000. Disponível em: 〈http://www.amazonia.org.br/arquivos/13213. pdf〉. Acesso em: 10 jun. 2018.

. Causas do desmatamento da Amazônia brasileira. Brasília: Banco Mundial, julho 2003.

MATIAS-PEREIRA, J. O processo de ocupação e de desenvolvimento da Amazônia: a implementação de políticas públicas e seus efeitos sobre o meio ambiente. Revista de Informação Legislativa, v. 34, n. 134, p. 75-86, 1997.

MELLO-THÉRY, N. A.; THÉRY, H. O planejamento territorial, o Estado e a Amazônia na obra de Bertha Becker: algumas reflexões. Revista Bibliográfica de Geografía y Ciencias Sociales, v. 19, n. 1103, 2014.

MENNIS, J. Generating surface models of population using dasymetric mapping. The Professional Geographer, v. 55, n. 1, p. 31-42, 2003.

MOLOTCH, $\mathrm{H}$. The city as a growth machine: toward a political economy of place. American Journal of Sociology, v. 82, n. 2, p. 309-332, 1976.

MONTEIRO, A. M. V.; CARDOSO, A. C. D. Project URBISAmazônia: what is the nature of the urban phenomenon in the contemporary Amazônia? Cities, places and networks in the multi-scale confi guration of the urban setting in contemporary Amazônia. GLP News Letter, n. 8, p. 26-28, 2012.

MONTE-MÓR, R. L. M. Modernities in the jungle: extended urbanization in the Brazilian Amazon. Dissertation (Ph.D) - University of California, Los Angeles (UCLA), 2004. Unpublished.

. Urbanização extensiva e lógicas de povoamento: um olhar ambiental. In: SANTOS, M.; SOUZA, M. A.; SILVEIRA, M. L. (Ed.). Território, globalização e fragmentação. 1. ed. Hucitec/ Anpur, 1994. v. 1, p. 169-181.

MOURA, H. A.; MOREIRA, M. D. M. A população da região Norte: processos de ocupação e de urbanização recentes. Modelos e cenários para a Amazônia: o papel da ciência. Parcerias Estratégicas, v. 6, n. 12, p. 214-238, 2001.

NAEA - Núcleo de Altos Estudos Amazônicos. Plano de Desenvolvimento Regional Sustentável da Região de Integração Xingu. Belém: UFPA, 2009.

NAZARETH, T.; BRASIL, M.; TEIXEIRA, P. Manaus: crescimento populacional e migrações nos anos 1990. Informe Gepec, v. 121, número especial, p. 488-502, 2011. 
NEVES, P. C. B.; MENEZES, R. C.; PENA, H. W. A. Análise da dinâmica das atividades econômicas predominantes no município de Placas, região de integração do Xingu-Pará-Brasil. Observatorio de la Economía Latinoamericana, n. 194, 2011.

PERZ, S. G.; ARAMBURÚ, C.; BREMNER, J. Population, land use and deforestation in the Pan Amazon Basin: a comparison of Brazil, Bolivia, Colombia, Ecuador, Perú and Venezuela. Environment, Development and Sustainability, v. 7, n. 1, p. 23-49, 2005.

PRATES, R. C. 0 desmatamento desigual na Amazônia brasileira: sua evolução, suas causas e conseqüências sobre o bem-estar. 2008. 160 f. Tese (Doutorado em Ciências: Economia Aplicada) - Universidade de São Paulo (USP), São Paulo, 2008.

PRATES, R. C.; BACHA, C. J. C. Os processos de desenvolvimento e desmatamento da Amazônia. Economia e Sociedade, v. 20, n. 3, p. 601-636, 2011.

RIBEIRO, R.; AMARAL, S.; MONTEIRO, A. M. V. A desconcentração da população urbana nas cidades paraenses: geoinformação no estudo do descompasso entre o crescimento da população e da extensão de áreas urbanas. In: XVIII SIMPÓSIO BRASILEIRO DE SENSORIAMENTO REMOTO. Anais... Santos: Inpe, 2017.

RIBEIRO, W. D. O. Entre a metrópole e a cidade média: a complexidade das interações espaciais e das dinâmicas de centralidade da cidade de Castanhal, no nordeste paraense. Geo USP Espaço e Tempo, v. 20, n. 1, p. 115-129, 2016.

RICHARDS, P.; VANWEY, L. Where deforestation leads to urbanization: how resource extraction is leading to urban growth in the Brazilian Amazon. Annals of the Association of American Geographers, v. 105, n. 4, p. 806-823, 2015.

RIVERO, S.; ALMEIDA, O.; ÁVILA, S.; OLIVEIRA, W. Pecuária e desmatamento: uma análise das principais causas diretas do desmatamento na Amazônia. Nova Economia, v. 19, n. 1, p. 41-66, 2009.

SCHOR, T.; OLIVEIRA, J. A. Reflexões metodológicas sobre o estudo da rede urbana no Amazonas e perspectivas para a análise das cidades na Amazônia brasileira. Revista ACTA Geográfica, edição especial Cidades na Amazônia Brasileira, p. 15-30, 2011.

SELDEN, T. M.; SONG, D. Environmental quality and development: is there a Kuznets curve for air pollution emission? Journal of Environmental Economics and Management, v. 27, p.147-162, 1994.

SMULDERS, S.; BRETSCHGER, L. Explaining environmental Kuznets curves: how pollution induces policy and new technologies. Tilburg University, 2000 (Working paper, n. 2000-95).

SOARES-FILHO, B. S. Fragmentação da paisagem florestal em função da estrutura e dinâmica fundiária no norte do Mato Grosso. In: X SIMPÓSIO BRASILEIRO DE SENSORIAMENTO. Anais... Foz do Iguaçu: Inpe, 2001.

SOUZA, N. S. A. Amazônia brasileira: processo de ocupação e a devastação da floresta. Boletim Científico, Brasília, ano 9, n. 32/33, p. 199-235, 2010.

TRITSCH, I.; LE TOURNEAU, F. M. Population densities and deforestation in the Brazilian Amazon: new insights on the current human settlement patterns. Applied Geography, v. 76, p. 163-172, 2016.

Dynamiques de peuplement et déforestation en Amazonie brésilienne entre 2000 et 2010: un regard basé sur les données statistiques et spatiales. In: COLLOQUE INTERNATIONAL ENVIRONNEMENT ET GÉOMATIQUE: APPROCHES COMPARÉES FRANCE-BRÉSIL. Actes... Rennes, France: Université Rennes 2, 2014.

VALERIANO, D. M.; ESCADA, M. I. S.; CÂMARA, G.; AMARAL, S.; MAURANO, L. E.; RENNÓ, C. D.; ALMEIDA, C.; MONTEIRO, A. M. V. Dimensões do desmatamento na Amazônia brasileira. In: 
MARTINE, G. (Ed.). População e sustentabilidade na era das mudanças ambientais globais: contribuições para uma agenda brasileira. Belo Horizonte: Abep, 2012. p. 223-238.

WRIGHT, S. J.; MULLER-LANDAU, H. C. The future of tropical forest species. Biotropica, v. 38, n. 3, p. 287-301, 2006.

\section{Sobre os autores}

Renata Maciel Ribeiro é mestre em Sensoriamento Remoto no Instituto Nacional de Pesquisas Espacias (Inpe) e cientista ambiental pela Universidade Federal Fluminense (UFF).

Silvana Amaral é doutora em Engenharia pela Escola Politécnica da Universidade de São Paulo (USP), mestre em Sensorimento Remoto pelo Instituto Nacional de Pesquisas Espaciais (Inpe) e ecóloga pela Universidade Estadual Paulista (Unesp) de Rio Claro.

Antônio Miguel Vieira Monteiro é doutor em Engenharia Eletrônica e Controle/Ciência da Computação pelo Centro de Ciências Espacias da Escola de Engenharia e Ciências Aplicadas da Universidade de Sussex, mestre em Computação Aplicada pelo Instituto Nacional de Pesquisas Espaciais (Inpe) e engenheiro elétrico pela Universidade Federal do Espírito Santo (Ufes).

Ana Paula Dal'Asta é doutora em Sensoriamento Remoto pelo Instituto Nacional de Pesquisas Espaciais (Inpe), mestre e graduada em Geografia pela Universidade Federal de Santa Maria (UFSM).

\section{Endereço para correspondência}

Renata Maciel Ribeiro

Rua Alabastro, 49, Jardim São José

12216-260 - São José dos Campos-SP, Brasil

Silvana Amaral

Av. dos Astronautas, 1.758, Jardim da Granja

12227-010 - São José dos Campos-SP, Brasil

Antônio Miguel Vieira Monteiro

Av. dos Astronautas, 1.758, Jardim da Granja

12227-010 - São José dos Campos-SP, Brasil

Ana Paula Dal'Asta

Av. Adhemar de Barros, 1737, Ap. 103, Jardim São Dimas

12245-010 - São José dos Campos-SP, Brasil

\section{Abstract}

The urbanization and forest conversion processes in the Paraense Amazon - a multiescalar study

In the Brazilian Amazon, dynamics of urbanization and forest conversion have complex logics, and are dependent on factors and agents operating at different levels. This article explores the spatial and temporal evolution of urbanization and forest conversion in the Amazon region from measurable elements present in these processes: urban expansion, observable dimensions of urbanization processes, and deforestation, a measure of forest conversion processes. The identification of similar spatiotemporal patterns, evaluated according to trends in the evolution 
of the degree of urbanization and the increase of deforestation in the years 2000, 2010 and 2014, was the basis for proposing a typology of relation between urban expansion and deforestation for the states of the Brazilian Legal Amazon and municipalities of Pará State. The study also explored the relation between urban expansion and deforestation, using Geographically Weighted Regression (GWR), observing two spatial units of analysis for Pará State: the municipal boundaries and a regular grid $(20 \times 20 \mathrm{~km})$. This multiscale approach evidenced the difficulty in establishing conclusive relationships regarding co-occurrence, or agreement, between the evolution of urbanization and forest conversion processes. Our results aim to establish an agenda on regional development models which take the urban phenomenon as essential for a socially just and environmentally responsible Amazon.

Keywords: Amazon. Urbanization. Deforestation. Spatial analysis.

\section{Resumen}

Los procesos de urbanización y conversión selvática en la Amazonia Paraenanse - un estudio multiescalar

En la Amazonia brasileña las dinámicas de urbanización y conversión selvática poseen lógicas complejas que dependen de factores y agentes que actúan en diferentes escalas. Este artículo explora la evolución espacial y temporal de la urbanización y la conversión selvática en la Amazonia a partir de elementos mensurables presentes en estos procesos: la expansión urbana, dimensión observable de los procesos de urbanización, y la deforestación, una medida de los procesos de conversión selvática. La identificación de patrones espaciotemporales similares, evaluados en cuanto a las tendencias de evolución temporal del grado de urbanización y del incremento de deforestación en los años 2000, 2010 y 2014 fueron la base para la propuesta de una tipología de las relaciones entre expansión urbana y deforestación para los municipios del Pará. El estudio exploró también las relaciones entre expansión urbana y deforestación, mediante el uso de la regresión geográficamente ponderada (GWR), observando dos unidades espaciales de análisis para el Pará: los límites municipales y una rejilla con celdas (20x20km). Este enfoque multiescalar evidenció la dificultad para establecer relaciones concluyentes en cuanto a la coocurrencia, o la concordancia, entre los procesos de urbanización y conversión selvática. Los resultados contribuyen al establecimiento de una agenda sobre modelos de desarrollo regional que retome lo urbano como esencial para una Amazonia socialmente justa y ambientalmente responsable.

Palabras clave: Amazonia. Urbanización. Deforestación. Análisis espacial. 


\section{ANEXO}

Resultados das regressões não espaciais para os municípios e células no estado do Pará

\begin{tabular}{|c|c|c|}
\hline \multicolumn{3}{|c|}{ Municípios } \\
\hline & $\begin{array}{c}\log (\Delta \text { Área Urb. })=f \log (\Delta \text { Desmat. } \\
\text { Acum.) }\end{array}$ & $\begin{array}{c}\log (\Delta \text { Pop. Urb. })=f \text { Log }(\Delta \text { Desmat. } \\
\text { Acum.) }\end{array}$ \\
\hline $\mathrm{R}^{2}$ ajust. & 0,12 & 0,05 \\
\hline Akaike & 167,4 & 250,81 \\
\hline$\beta$ & 0,257 & 0,248 \\
\hline Moran & 0,39 & 0,30 \\
\hline Jarque-Bera & 1,95 (p valor: 0,377 ) & $11,03$ ( $p$ valor: 0,004$)$ \\
\hline Breusch-Pagan & $5,54$ ( $p$ valor: 0,018$)$ & 6,88 (p valor: 0,008) \\
\hline Koenker-Basset & 4,37 (p valor: 0,036) & 4,12 (p valor: 0,042) \\
\hline \multicolumn{3}{|c|}{ Células } \\
\hline & $\begin{array}{c}\log (\Delta \text { Área Urb. })=f \log (\Delta \text { Desmat. } \\
\text { Acum.) }\end{array}$ & $\begin{array}{c}\log (\Delta \text { Pop. Urb. })=f \log (\Delta \text { Desmat. } \\
\text { Acum.) }\end{array}$ \\
\hline $\mathrm{R}^{2}$ ajust. & 0,03 & 0,03 \\
\hline Akaike & 1312,19 & 450,82 \\
\hline$\beta$ & 0,238 & 0,289 \\
\hline Moran & 0,11 & 0,08 \\
\hline Jarque-Bera & 101,03 ( $p$ valor: 0,00) & $154,10$ ( $p$ valor: 0,00$)$ \\
\hline Breusch-Pagan & 1,07 (p valor: 0,30$)$ & 11,37 (p valor: 0,00$)$ \\
\hline Koenker-Basset & $0,60$ (p valor: 0,43$)$ & 4,01 (p valor: 0,04) \\
\hline
\end{tabular}

